\title{
Guidelines for Tuning the Excited State Hückel-Baird Hybrid Aromatic Character of Pro-Aromatic Quinoidal Compounds
}

Sílvia Escayola, ${ }^{\mathrm{a}, \mathrm{b} \#}$ Claire Tonnelé, ${ }^{\mathrm{b} \#}$ Eduard Matito, ${ }^{\mathrm{b}, \mathrm{c}}$ Albert Poater, ${ }^{\mathrm{a}}$ Henrik Ottosson, ${ }^{\mathrm{d} *}$ Miquel Solà ${ }^{\mathrm{a}, *}$ and David Casanova ${ }^{\mathrm{b}, \mathrm{c} *}$

a Institute of Computational Chemistry and Catalysis and Department of Chemistry, University of Girona, C/ M. Aurèlia Capmany, 69, 17003 Girona, Catalonia, Spain.

${ }^{b}$ Donostia International Physics Center (DIPC), Donostia, Euskadi, Spain

${ }^{c}$ Ikerbasque Foundation for Science, 48011 Bilbao, Euskadi, Spain

${ }^{d}$ Department of Chemistry - Angström Laboratory, Uppsala University, SE-751 20, Uppsala, Sweden

${ }^{\#}$ S.E. and C.T. have contributed equally to this work.

Abstract: Pro-aromatic molecules are molecules that in a higher-energy diradicaloid state are significantly influenced by resonance structures in which conjugated rings take on Hückelaromatic character. It has been argued in recent studies that there are also pro-aromatic molecules that adopt central units with $4 n \pi$-electron Baird-aromatic character in their lowest triplet diradical states $\left(\mathrm{T}_{1}\right)$, although detailed analysis suggests that these compounds are better labelled as $\mathrm{T}_{1}$ Hückel-Baird hybrid molecules, where Hückel-aromaticity is the dominant form. Herein, we consider a series of symmetrically substituted conjugated rings with potential Baird aromaticity in the lowest-lying excited triplet and singlet states. Our results allow us to establish general guidelines for the rational design of molecules with excited state Hückel/Baird aromaticity in pro-aromatic quinoidal compounds. In particular, we found two main strategies to promote a high Baird aromatic character of the central ring, namely, by using either $(i)$ anionic and small conjugated rings with electron donating groups as substituents and small exocyclic groups with electron withdrawing substituents, or (ii) electron deficient conjugated rings with exocyclic electron-donor substitution. 


\section{Introduction}

Molecules when excited from their ground state $\left(\mathrm{S}_{0}\right)$ to their lowest electronically excited states often change their electronic structure considerably, which impacts on a range of important molecular properties. For example, the reactivity of a molecule in its excited state often differs markedly from that in its $\mathrm{S}_{0}$ state. $^{1}$ Also, the charge distribution within a molecule is normally altered upon excitation, and consequently, its interaction with the surrounding medium. Excited states can be obtained as electronic transitions with large hole/electron spatial overlap, or alternatively, induce substantial displacements of the excited electrons. The latter implies charge transfer (CT) character as exemplified by metal-to-ligand charge transfer (MLCT) $)^{2-3}$ states in transition metal coordination complexes and by twisted-intramolecular charge transfer $(\mathrm{TICT})^{4}$ states observed in many flexible $\pi$-conjugated organic chromophores. The electronic structure changes upon excitation are influenced by a number of factors; those that are intrinsic to the molecule and those that are extrinsic. The bonding and antibonding features of the orbitals populated in the excited state is one of the most obvious intrinsic factors, whereas the polarity of the surrounding solvent or medium (e.g., the active site within a protein) constitutes a typical example of possible extrinsic factors. An important intrinsic factor is the ability of a molecule to switch its electronic structure from a pro-aromatic structure to an aromatic one upon excitation. $^{5-7}$

Now, aromaticity and antiaromaticity are concepts that come in various forms. Baird's rule ${ }^{8-14}$ for the lowest $\pi \pi^{*}$ triplet state $\left(T_{1}\right)$ states that $4 n \pi$-electron conjugated monocycles are aromatic while $(4 n+2) \pi$-electron cycles are antiaromatic, and according to recent computational as well as experimental studies, it often seems to also apply to the lowest singlet excited state $\left(\mathrm{S}_{1}\right) \cdot{ }^{15-23}$ Yet, also Hückel-aromaticity can impact on features in the excited states, and it was recently shown that properly substituted fulvenes have $\mathrm{S}_{2}$ states of CT character with a cyclopentadienyl anionic ring, i.e., a Hückel aromatic ring. ${ }^{24}$ Interestingly, one 
may even have excited states which are influenced simultaneously by Baird- and Hückelaromaticity, as has been revealed for a 2,7-dimethylenemethano[10]annulene exo-substituted with two 5-dicyanomethyl-thiophene moieties at the peripheries (TMTQ). Tovar, Casado, and co-workers explored TMTQ in its $\mathrm{T}_{1}$ state and reasoned that this compound is Baird-aromatic, ${ }^{25}$ although it was later shown to be a triplet state Hückel-Baird hybrid aromatic molecule with $88 \%$ Hückel-aromatic and 12\% Baird-aromatic character (vide infra). ${ }^{26}$ Experimental findings, combined with some computational data, on the lowest singlet excited state of the same molecule have also recently been published. ${ }^{27}$

Research on excited state Baird-aromaticity has intensified in the last decade. ${ }^{28-32}$ Yet, comprehensive and critical analyses combined with solid computational assessments are required for the proper interpretation of experimental data as there is presently no spectroscopic technique that can be used as the sole method to evaluate excited state aromaticity in a similar manner as ${ }^{1} \mathrm{H}$ NMR spectroscopy can be used to assess aromaticity in the $\mathrm{S}_{0}$ state. The correctness of the interpretations is crucial as only then can the Baird-aromaticity concept be developed into a tool that is useful to the design of molecules with targeted optoelectronic properties for potential use in, e.g., organic electronics. ${ }^{33}$ Now, can the Baird-aromatic character in (symmetrically) substituted conjugated quinoidal rings, the class of molecules to which TMTQ belongs to, be increased either $(i)$ by going from the $\mathrm{T}_{1}$ to the $\mathrm{S}_{1}$ state, (ii) by using different central pro-aromatic units, (iii) by considering longer or shorter side groups, and/or (iv) by altering their structures in some other way?

Pentafulvenes ${ }^{34}$ are not considered as pro-aromatic, yet they display some shift in electron density into the five-membered ring (5-MR) in the $\mathrm{S}_{0}$ state and out from that ring in their $\mathrm{T}_{1}$ and $\mathrm{S}_{1}$ states as they adhere to Hückel's $4 n+2$ rule in $\mathrm{S}_{0}$ and Baird's $4 n$ rule in $\mathrm{T}_{1}{ }^{35}$ Thus, they adapt to the different electron counting rules for aromaticity in different states, and accordingly, act as "aromatic chameleons". ${ }^{36}$ However, the CT character in the excited states is 
rather small, except for fulvenes with strong acceptor substituents at the exocyclic carbon and donor substituents at the endocyclic positions. In such compounds one can, according to computations, drive the triplet state to be the ground state (a $\mathrm{T}_{0}$ state) with a Baird-aromatic cyclopentadienyl cationic ring. ${ }^{36}$ Yet, despite the rather modest CT character of most fulvenes in their lowest excited states, they still display significant solvatochromism. ${ }^{19}$

Numerous pro-aromatic molecules can be designed which on paper can be labelled as Hückel-Baird hybrids in their lowest triplet states (Figure 1). Here, an interesting aspect is the difference in the number of $\mathrm{CC} \pi$-bonds between the Hückel-aromatic and the Baird-aromatic resonance structures in the triplet state. For pentafulvene, which is not a HückelBaird hybrid, the difference is one, while for the neutral pro-aromatic molecules, i.e., paraxylylene and 2,7-dimethylenemethano[10]annulenes, the difference is two. In contrast, for the three charged pro-aromatic molecules in their triplet states, the difference is one, indicating that less number of $\pi$-bonds formally need to be broken. Hence, an influence of the Baird-aromatic structure in the ionic compounds should imply a smaller energy penalty. Additionally, as the charge separation is larger in the Baird-aromatic resonance structures for the neutral molecules $(-1,+2,-1)$ than for the charged ones (either $-1,+1,-1$ or $+1,-1,+1)$, we postulate that it could be more facile to develop stronger Baird-aromatic character in the $\mathrm{T}_{1}$ and $\mathrm{S}_{1}$ states of the latter ones. 
Pentafulvene

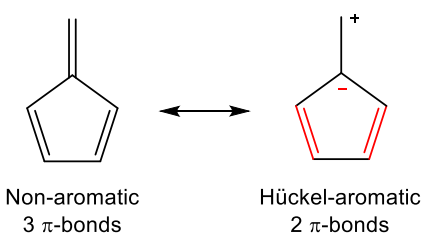

1,3-Dimethylenecyclopentadienyl anion

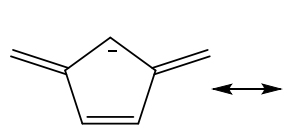

Non-aromatic $3 \pi$-bonds

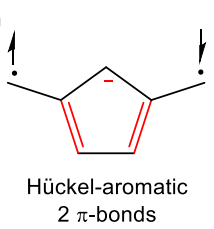

para-Xylylene

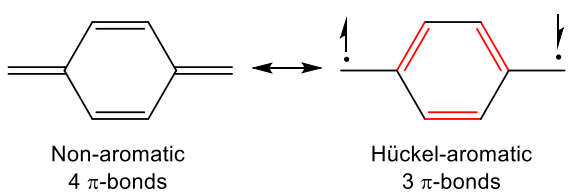

1,4-Dimethylenetropylium cation

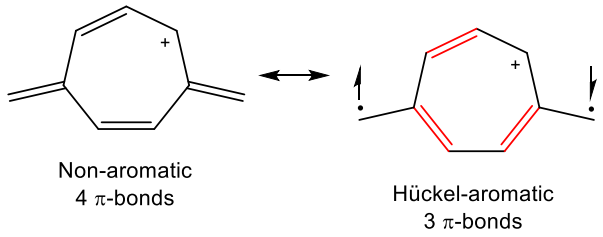

1,5-Dimethylenecyclononatetraenyl anion

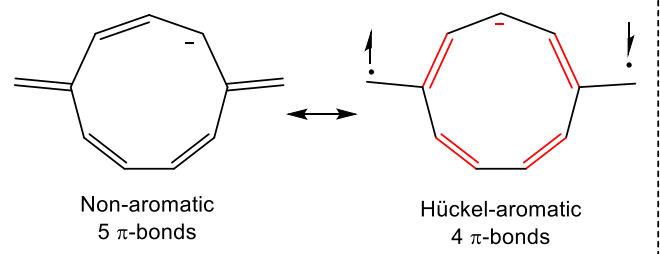

2,7-Dimethylenemethano[10]annulene

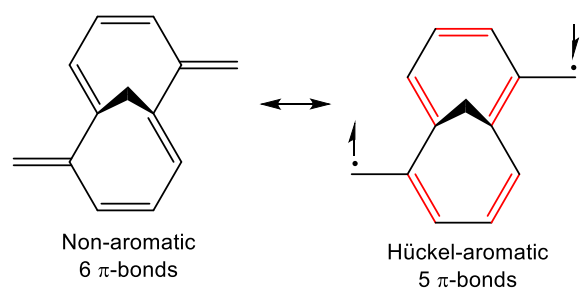

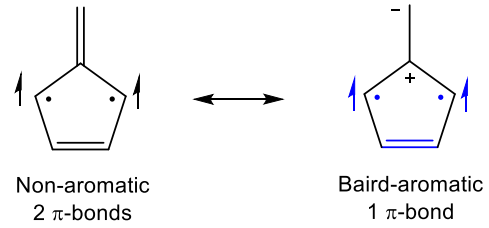

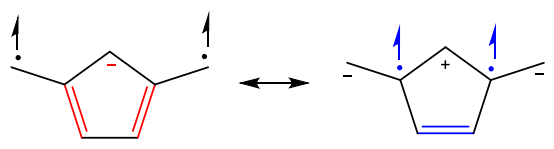

Hückel-aromatic Baird-aromatic $2 \pi$-bonds $1 \pi$-bond
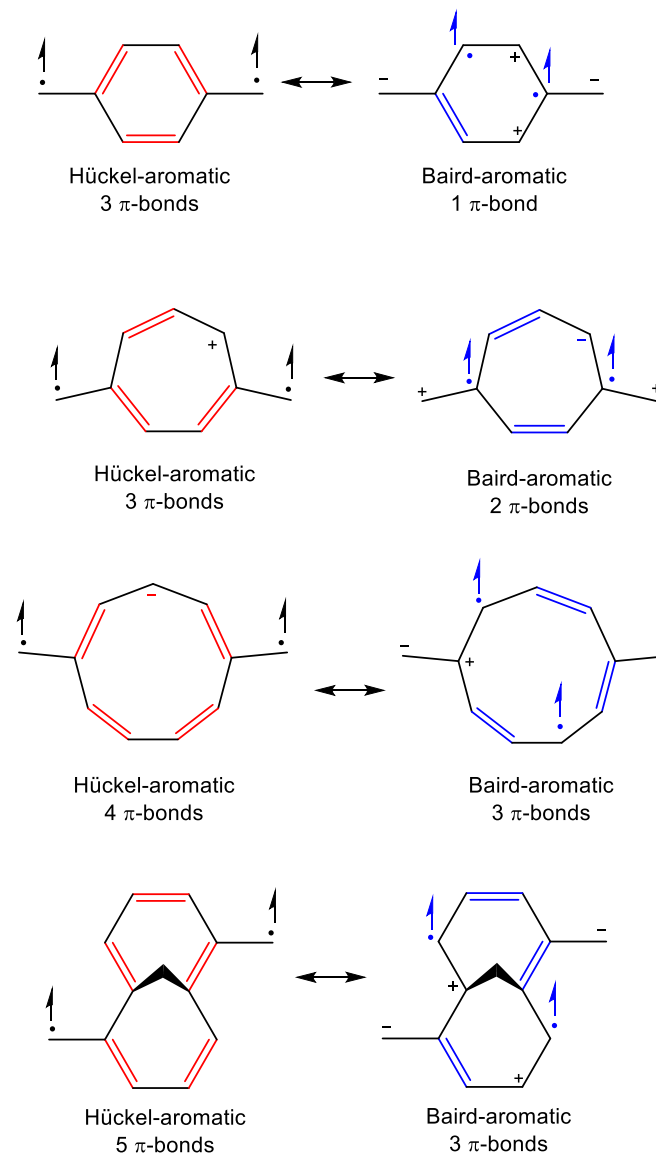

Figure 1. A few of the non-aromatic, Hückel-aromatic, and Baird-aromatic resonance structures of the parent fulvenes and dimethyleneannulenes in their lowest-lying singlet and triplet states. $\pi$-Bonds and electron pairs involved in the Hückel-aromatic cycles are displayed in red and Baird-aromatic ones in blue. 
Recently, the excited state Baird-aromaticity of TMTQ was once again explored, ${ }^{27}$ this time in its low-lying (singlet) excited state where it was argued to display photoinduced two-electron CT from the central M10A ring (10 $\pi$-electrons) to the two 5dicyanomethyl-thiophene (DT) peripheric units (Figure 2). The allegedly strong CT character of the excited singlet was experimentally determined by means of the frequency displacement of nitrile stretching vibrational mode and by the dependence of excited state dynamics with solvent polarity. Yet, both phenomena do not univocally imply the CT nature of the transition, and several computational analyses of substituted conjugated rings reveal the lack of strong CT character of low-lying excitations. Moreover, the charge on the $\mathbf{M 1 0 A}^{37}$ fragment in the $\mathrm{T}_{1}$ state of TMTQ was found to be $0.237 \mathrm{e}$, indicating that the contribution of the Baird aromatic TMTQ-c resonance structure (Figure 2) is ca. $12 \% .^{26}$
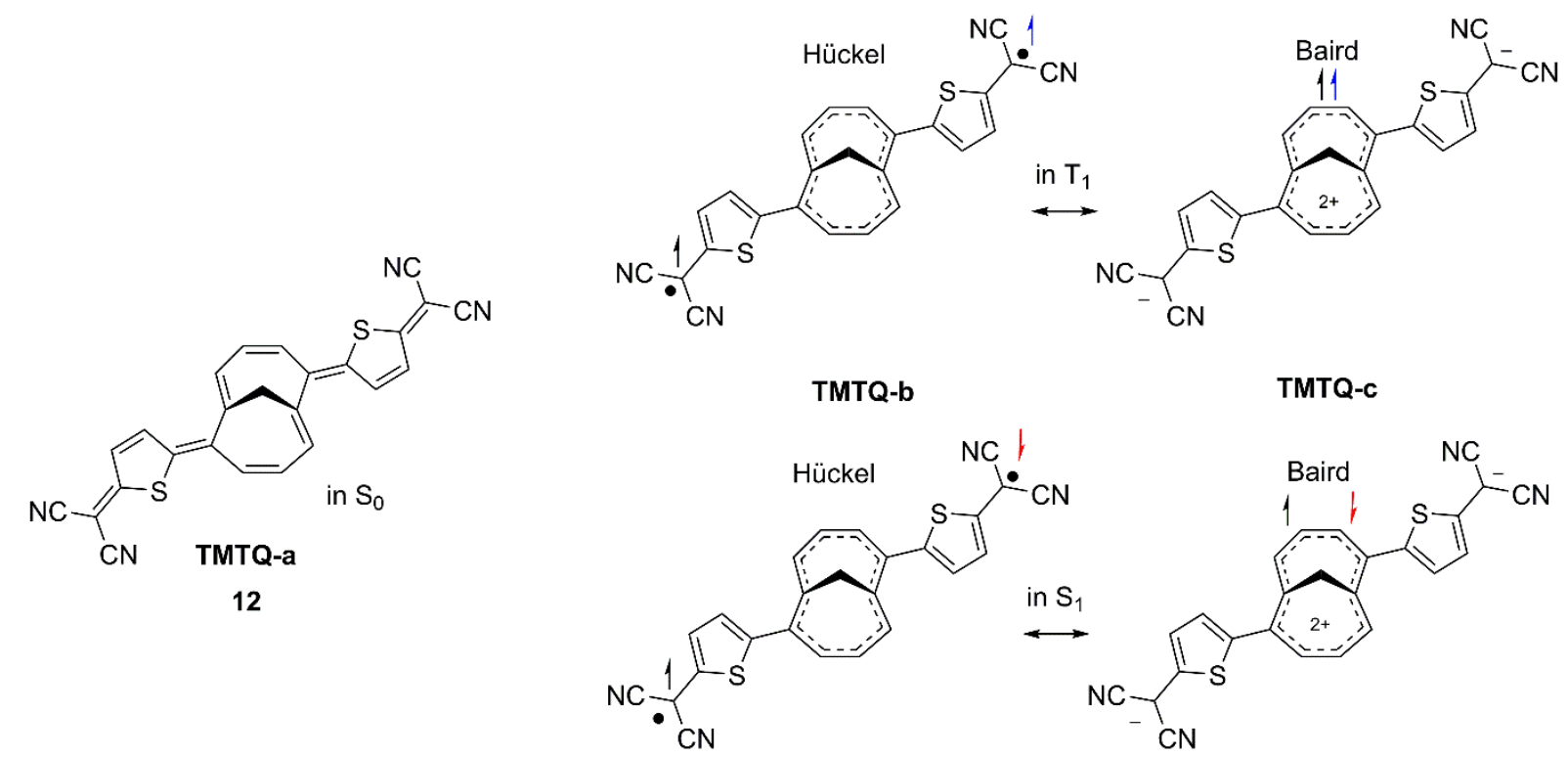

Figure 2. Covalent, diradical, and ionic resonance structures of importance for 10R-T (TMTQ) involved in the description of $\mathrm{S}_{0}, \mathrm{~S}_{1}$, and $\mathrm{T}_{1}$ states.

The present work explores to what extent a range of different Hückel-Baird hybrid compounds (Figure 3) have the ability to adopt Baird aromatic character in the lowest singlet 
and triplet excited states. The study intends to solve several important questions. Are there proaromatic Hückel-Baird hybrid compounds for which the Baird-aromatic description dominates in the $T_{1}$ state? How similar are the $S_{1}$ and $T_{1}$ states in character? What is the importance of CT in the Baird-aromatic character of $S_{1}$ and $T_{1}$ ? How can we induce, increase and rationalize the Baird-aromatic character of the $T_{1}$ and $S_{1}$ states through different central rings and exocyclic substituents? Ultimately, by answering these questions, we aim to develop general guidelines for the design of hybrid Hückel-Baird pro-aromatic species with strong Baird-aromatic character in their lowest excited states.<smiles>[R]C([R])=C1C=CC(=C([R])[R])C1</smiles>

5R: $\mathrm{R}$ and $\mathrm{R}^{\prime}=\mathrm{CN}$ 5R-2H+: $\mathrm{R}=\mathrm{CNH}^{+}, \mathrm{R}^{\prime}=\mathrm{CN}$ 5R-4H+: $\mathrm{R}$ and $\mathrm{R}^{\prime}=\mathrm{CNH}^{+}$<smiles>[R]C(C)=c1c([R])c([R])c(=C([R])[N])c([R])c1[R]</smiles>

6R: $\mathrm{R}=\mathrm{CN}, \mathrm{R}^{\prime}=\mathrm{H}$ 6R-2H+: $\mathrm{R}=\mathrm{CNH}^{+}, \mathrm{R}^{\prime}=\mathrm{H}$ 6Ra: $R=C N$ and $R^{\prime}=F$<smiles>N#CC(C#N)=C1C=CC(=C(C#N)C#N)/C=C\C=C/1</smiles>

9R

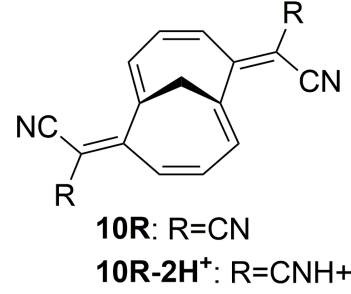<smiles>N#CC(C#N)=c1ccc(=C2C=CC(=c3ccc(=C(C#N)C#N)s3)C2)s1</smiles>

5R-T<smiles></smiles>

9R-T<smiles>[R]C1=CC=C([R])C1=C1C([R])=C([R])C(=C2C([R])=CC=C2[R])C1[R]</smiles>

5R-5a:R=H, R'=H 5R-5b:R=Me, $\mathrm{R}^{\prime}=\mathrm{Me}$ $5 R-5 c: R=C N, R^{\prime}=C l$

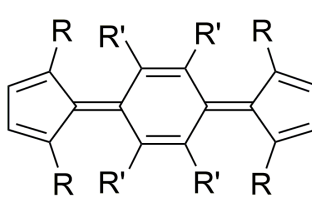

6R-5a:R=H, R'=H $6 R-5 b: R=M e, R^{\prime}=M e$ $6 \mathrm{R}-5 \mathrm{c}: \mathrm{R}=\mathrm{CN}, \mathrm{R}^{\prime}=\mathrm{Cl}$<smiles>N#CC(C#N)=c1ccc(=c2ccc(=c3ccc(=C(C#N)C#N)s3)cc2)s1</smiles>

6R-T<smiles>N#CC(C#N)=c1ccc(=C2C=CC=C(c3ccc(C#N)s3)CC2=CC=[Zn])s1</smiles><smiles>C1=CC1=c1ccc(=C2C=C2)cc1</smiles>

6R-3a<smiles>[R16][R16]=c1ccc(=C2C(N)=C2N)cc1</smiles>

6R-3b<smiles>[R]C1=C([R])C1=C1C2=C(C(=C3C([R])=C3[R])[SiH]1C)[SiH](C)C[SiH]2C</smiles>

6R-3c: $\mathrm{R}=\mathrm{NMe}_{2}$

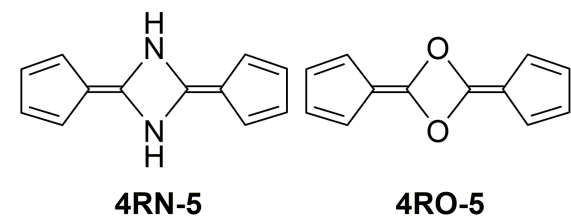

4RN-5

4RO-5<smiles></smiles>

7Ra<smiles>C1=CC(=C2NC=CN2)C=CC(=C2NC=CN2)C=C1</smiles>

7Rb

Figure 3. The compounds investigated in this study. 


\section{Results and Discussions}

\section{Excited state aromaticity in conjugated rings}

This section is organized in two parts. We first discuss the Hückel-Baird aromatic character in the $T_{1}$ and $S_{1}$ states of molecules with conjugated rings symmetrically substituted with two dicyanomethylene units labelled as $\boldsymbol{n} \mathbf{R}$ (Figure 3). In the second part, we explore species in which one thiophene unit has been added in each of the two side-arms ( $\boldsymbol{n} \mathbf{R}-\mathbf{T}$ compounds).

The lowest singlet and triplet states of $\boldsymbol{n R}$ with $n=5,6,9$, and 10 ( $n$ being the number of $\mathrm{C}$ atoms in the central ring), i.e., compounds $5 \mathbf{R}, 6 \mathbf{R}, 9 \mathbf{R}$, and $10 \mathbf{R}$, are obtained as the single electron occupancy of the highest occupied molecular orbital (HOMO) and the lowest unoccupied molecular orbital (LUMO). Both frontier $\pi$-orbitals are well delocalized over the entire molecule (Figure 4). Vertical excitation energies from the singlet ground state $\left(\mathrm{S}_{0}\right)$ to $\mathrm{T}_{1}$ in $\mathbf{5 R}$ and $\mathbf{6 R}$ are within the 1.1-1.2 eV range (TDA-B3LYP), and about $0.2 \mathrm{eV}$ higher in $\mathbf{9 R}$ and 10R (Table S18). Vertical energies to $S_{1}$ of $\boldsymbol{n} \mathbf{R}$ are approximately twice the corresponding triplet energies, except in $\mathbf{6 R}$ for which the transition energy to the first excited singlet is sensibly higher. Relaxation on the $T_{1}$ and $S_{1}$ potential energy surfaces (PES) stabilizes the lowest triplet by about $0.2-0.3 \mathrm{eV}$ and considerably more in the first excited singlet. The relative energies of $T_{1}$ and $S_{1}$ states computed with other functionals (CAM-B3LYP, $\omega B$ 97X-D and M06-2X) yield very similar results (see Tables S1 and S2). 


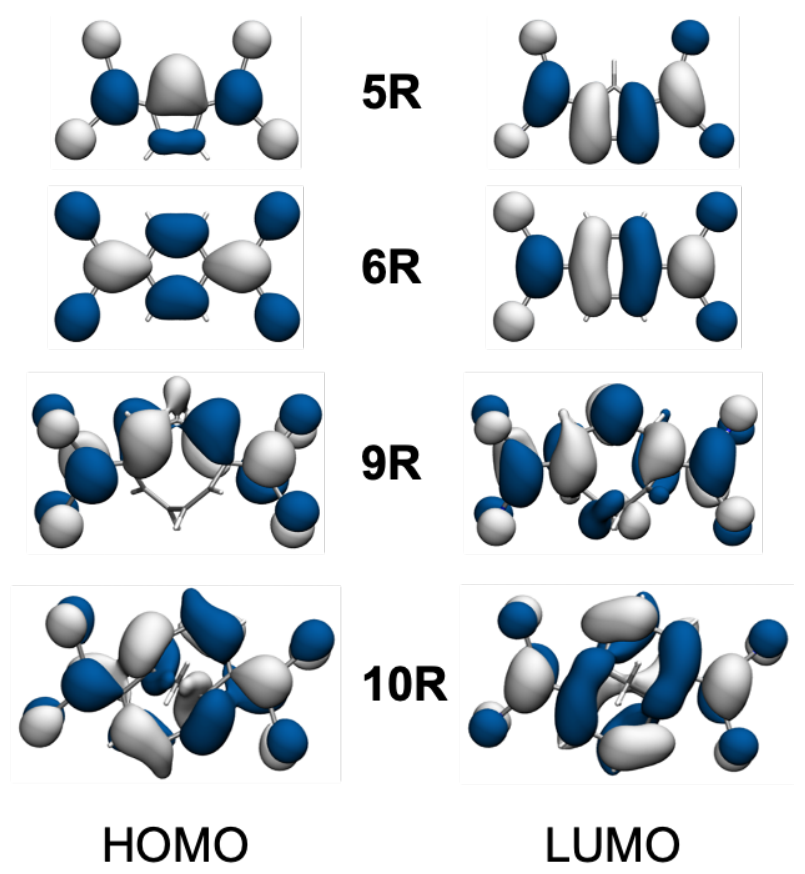

Figure 4. Frontier molecular orbitals HOMO (left) and LUMO (right) for the $\boldsymbol{n} \mathbf{R}(n=5,6,9$, and 10) series. Plots of HOMO-1 and LUMO+1 are given in the Supporting Information.

Optimized molecular geometries in the ground and excited $\left(\mathrm{T}_{1}\right.$ and $\left.\mathrm{S}_{1}\right)$ electronic states of $\mathbf{5 R}$ and $\mathbf{6 R}$ feature planar conjugated rings. On the other hand, the 9-MR in the ground and excited singlet states of $\mathbf{9 R}$ is rather contorted, but planarizes considerably in the $\mathrm{T}_{1}$ state. Although the structure of M10A in $10 R$ is strongly restricted by the methano-bridge, the conjugated ring flattens mildly in the lowest excited states. Moreover, minimal energy structures of $T_{1}$ and $S_{1}$ for the four $\boldsymbol{n} \mathbf{R}$ molecules exhibit a systematic bond length equalization with respect to the bond alternation pattern in the ground state (Figure 5a), which points out an increase of the aromatic character of the central rings when going from the ground to the lowest excited triplet and singlet states. Bond length changes in $\mathbf{5 R}$ and $\mathbf{9 R}$ when going from $\mathrm{S}_{0}$ to $\mathrm{S}_{1}$ are somewhat larger than those derived from the transition of $S_{0}$ to $T_{1}$, suggesting larger electronic structure rearrangements in the central ring in the excited singlet state. The observed bond length equalization is in line with the changes in the bond electron delocalization indices 
$(\mathrm{DIs})^{38-39}$ (Figure 5b) and are supported by the different methods we have employed to quantify the aromaticity. In particular, for the case of $\mathbf{5 R}$, the HOMA ${ }^{40-41}$ increases from -0.223 in $\mathrm{S}_{0}$ to 0.435 in $\mathrm{S}_{1}$ and 0.630 in $\mathrm{T}_{1}$ (Table S99), FLU ${ }^{42}$ decreases from 0.0397 in $\mathrm{S}_{0}$ to 0.0124 in $\mathrm{T}_{1}$ and 0.0122 in $\mathrm{S}_{1}$ (Tables $\mathrm{S} 86-\mathrm{S} 88$ ), NICS $(1)_{\mathrm{zz}}{ }^{43}$ changes from $6.97 \mathrm{ppm}$ in $\mathrm{S}_{0}$ to $-8.56 \mathrm{ppm}$ in $\mathrm{T}_{1}$ (Table S101), and GIMIC plots in Figure 6 (see Figures S35-S40 for the rest of the systems) show a more intense diatropic ring current for the $\mathrm{T}_{1}$ state than for $\mathrm{S}_{0}$. In fact, the mean bond current strength ${ }^{44-45}$ is diatropic for $\mathrm{T}_{1}\left(1.53 \mathrm{nA} \mathrm{T}^{-1}\right)$ and paratropic for $\mathrm{S}_{0}\left(-3.48 \mathrm{nA} \mathrm{T}^{-1}\right)$. Other electronic aromaticity measures ( $\mathrm{I}_{\text {ring }}$ and $\left.\mathrm{MCI}\right)^{46-49}$ provide similar trends (Tables $\mathrm{S} 90-\mathrm{S} 98$ ). Interestingly, for all analyzed states, all indices suggest a slightly higher aromaticity of the central ring in compounds $6 \mathbf{R}$ and $10 R$ than in $\mathbf{5 R}$ and $9 R$. Besides, structural relaxation on the excited triplet and singlet PESs induces an elongation of the two exocyclic $\mathrm{CC}$ bonds with a concomitant decrease of the corresponding DIs.
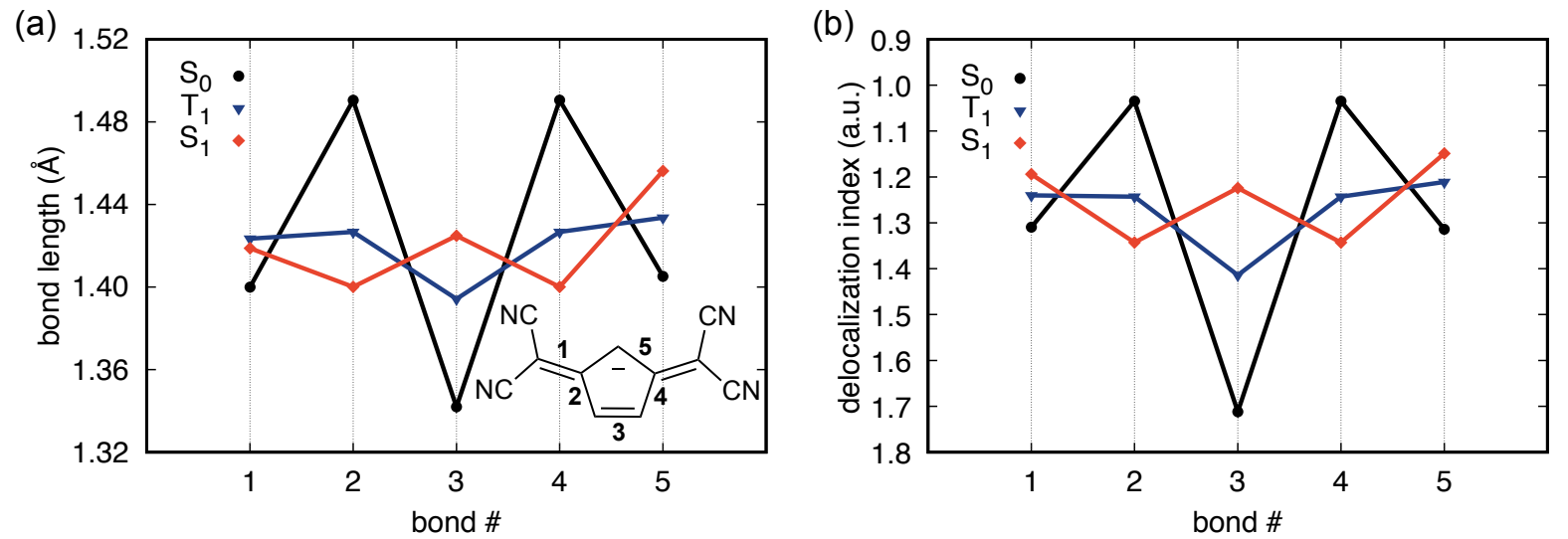

Figure 5. Molecular distribution of: (a) carbon-carbon bond lengths (in $\AA$ ) and (b) delocalization indices (in a.u.) of compound 5R. Bond labels are given in the inset. Bond length alternation (BLA, $\AA$ )/bond order alternation $(B O A, e)$ of $\mathrm{S}_{0}, \mathrm{~T}_{1}$, and $\mathrm{S}_{1}$ states of $\mathbf{5 R}$ are $0.094 / 0.382,0.016 / 0.081$, and 0.032/0.131, respectively. Bond lengths and DIs for the rest of the studied molecules are given in the Supporting Information. 

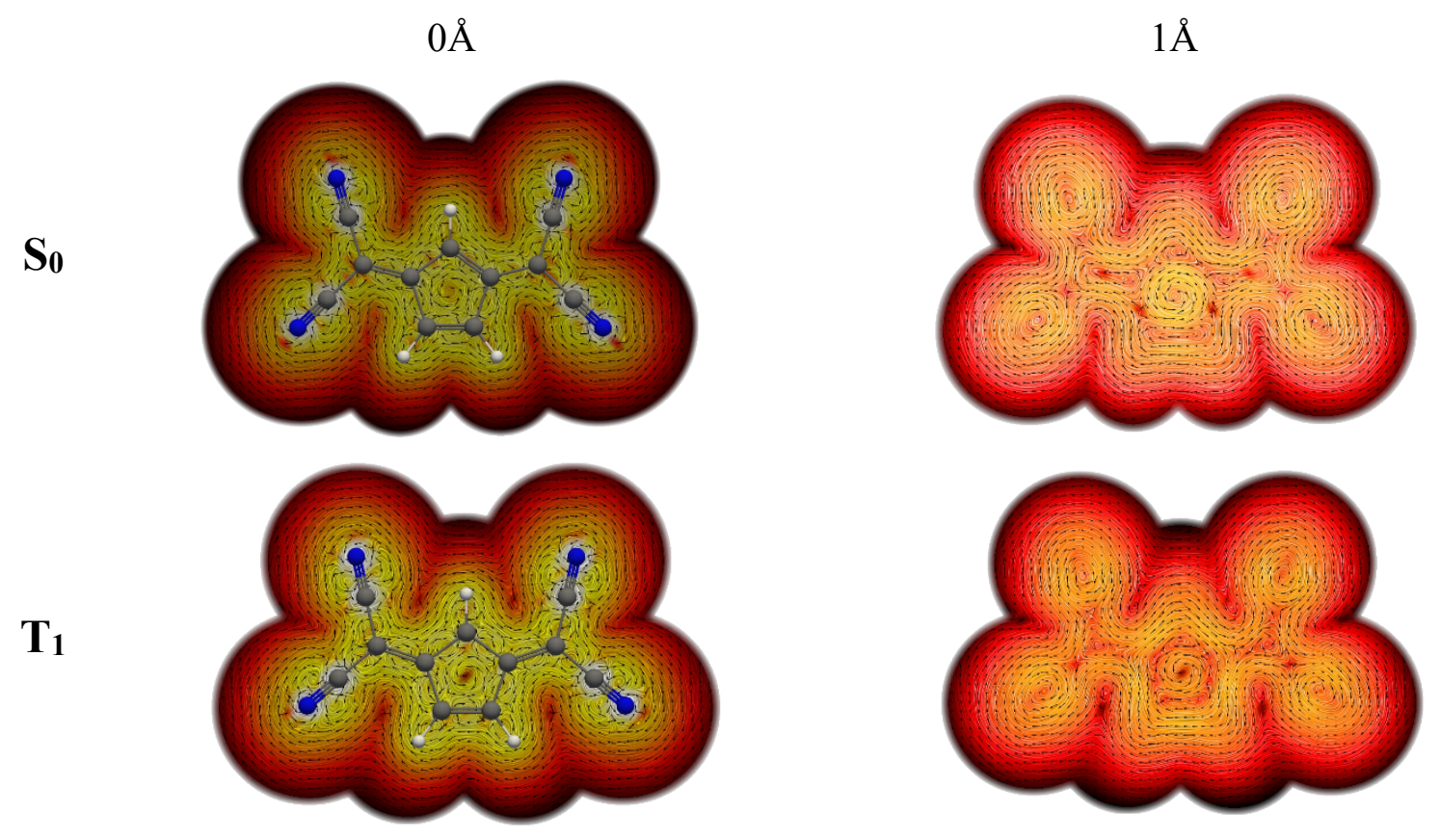

Figure 6. Representation of the current-density vector field for the $S_{0}$ and $T_{1}$ states of system 5R. Top view of the currents in the perpendicular plane with respect to the magnetic field vector $\mathrm{B}_{0}$ located at 0 and $1 \AA$ (left and right, respectively) above the molecular plane. White-yellow regions correspond to larger current values $\left(0.1 \mathrm{nA} \cdot \mathrm{T}^{-1}\right)$, while dark red to black correspond to vanishing current densities $\left(\leq 10^{-6} \mathrm{nA} \cdot \mathrm{T}^{-1}\right)$.

Therefore, structural analysis and (global) aromaticity indices manifest a transition from non-aromatic to aromatic character in the central ring of $\boldsymbol{n} \mathbf{R}$ compounds upon excitation to the lowest singlet and triplet states. In the following, we aim to uncover the details regarding the nature of the electronic structure in the excited state manifold, concretely their Hückel, Baird or Hückel-Baird hybrid character as shown in Figure 1.

Next, we analyze the $\alpha$ and $\beta$ components of the electron DIs corresponding to the $\mathrm{C}-\mathrm{C}$ bonds of the central ring in the $\mathrm{T}_{1}$ state of $\mathbf{5 R}, \mathbf{6 R}, \mathbf{9 R}$, and $10 \mathbf{R}$. The results in Tables S54-S85 show that the difference between the $\alpha$ and $\beta$ components of these DIs is never larger 
than 0.13 e. This difference is particularly small for compounds $\mathbf{6 R}$ and $\mathbf{1 0 R}$, indicating an almost identical contribution of the $\alpha$ and $\beta$ electrons to the covalent bond order of the $\mathrm{C}-\mathrm{C}$ bonds of the conjugated ring. Electronic indices (IND) can be separated into $\alpha$ and $\beta$ spin components $\left(\mathrm{IND}_{\alpha}\right.$ and $\left.\mathrm{IND}_{\beta}\right)$ and one can obtain $|\Delta \mathrm{IND}| / \mathrm{IND}$ values with $\Delta \mathrm{IND}=\mathrm{IND}_{\alpha}-\mathrm{IND}_{\beta}$ for the $T_{1}$ state (for $S_{1}$ the $\alpha$ and $\beta$ components are equivalent). These $|\Delta \mathrm{IND}| / \mathrm{IND}$ values can be used to quantify the Baird contribution in the $\mathrm{T}_{1}$ state. ${ }^{26} \mathrm{~A}$ low value of $|\Delta \mathrm{IND}| / \mathrm{IND}$ in the central ring suggests that the central $n$-MR is predominantly Hückel aromatic with the same number of $\alpha$ and $\beta \pi$-electrons, whereas a large value points towards a Baird aromatic ring unit with two more $\alpha$ than $\beta \pi$-electrons.

In the following, and through the rest of this report, we focus on the results obtained with the FLU index. Values obtained with other electronic indices $\left(\mathrm{I}_{\text {ring, }}\right.$ MCI, and $\left.\mathrm{AV}_{\min }{ }^{50}\right)$ can be found in the Supporting Information. $|\Delta \mathrm{FLU}| / \mathrm{FLU}$ values for the $\boldsymbol{n} \mathbf{R}$ series in their $\mathrm{T}_{1}$ states are $2.331\left({ }^{3} \mathbf{5 R}\right), 1.159\left({ }^{3} \mathbf{6 R}\right), 1.862\left({ }^{3} \mathbf{9 R}\right)$, and $0.911\left({ }^{3} \mathbf{1 0 R}\right)$, and these values should be compared to the $|\Delta \mathrm{FLU}| / \mathrm{FLU}$ results of the fully Baird aromatic reference species: ${ }^{3} \mathrm{C}_{5} \mathrm{H}_{5}{ }^{+}$(4.383), ${ }^{3} \mathrm{C}_{6} \mathrm{H}_{6}{ }^{2+}$ (4.693), ${ }^{3} \mathrm{C}_{9} \mathrm{H}_{9}{ }^{+}$(4.387), and ${ }^{3} \mathrm{C}_{11} \mathrm{H}_{10}{ }^{2+} \mathbf{M 1 0 A}^{2+}$ (1.999) (Table S105). The relatively low $|\triangle \mathrm{FLU}| / \mathrm{FLU}$ values denote strong Hückel character (with some Baird contribution) of the central ring in the triplet state of $6 \mathbf{R}$ and $10 R$. For $5 \mathbf{R}$ and $\mathbf{9 R}$, the Baird character is higher and close to $50 \%$. The lower involvement of the Baird form in the neutral 6R and $10 R$ when compared to the anionic $\mathbf{5 R}$ and $9 \mathbf{R}$ compounds is in line with the hypothesis based on the difference in the number of $\pi$-bonds between the quinoid and Baird-aromatic zwitterionic resonance structures in the charged vs. neutral compounds (Figure 1).

To further quantify the importance of the different resonance structures in the description of the $T_{1}$ and $S_{1}$ states of $\boldsymbol{n R}(n=5,6,9$, and 10), and, consequently, to assess the Hückel-Baird aromatic character of the conjugated central ring, we examine the charge and spin 
distributions using different schemes (Mulliken, Hirschfeld, NPA, CHELPG, and QTAIM, see Tables S20-S51). We focus here on the QTAIM results, but trends are similar for the rest of the methods. The results differ significantly for anionic (5R and $\mathbf{9 R})$ as compared to neutral (6R and 10R) molecules. For systems $\mathbf{5 R}$ and $\mathbf{9 R}$, both $T_{1}$ and $S_{1}$ states show a similar Baird aromatic character with charges in the 0.01-0.12 e range, indicating that the Baird character in these states is about $51 \%$ to $56 \%$. Similarly, the central ring spin densities of 1.006 e (5R) and 0.956 e (9R) suggest that the Baird contribution to the $\mathrm{T}_{1}$ state is around $50 \%$, in agreement with $|\Delta \mathrm{FLU}| / \mathrm{FLU}$ results. The atomic charges at the 6-MR obtained for the triplet state of $\mathbf{6 R}$ suggests an $18 \%$ Baird character. The $\mathrm{T}_{1}$ charge at central ring of $10 \mathrm{R}$ is higher $(0.499 \mathrm{e}, 25 \%$ Baird), in good agreement with an increase of spin density of $\mathbf{1 0 R}(0.684 \mathrm{e})$ with respect to $\mathbf{6 R}$ (0.351 e). Spin density plots show that the presence of spin density in the central ring of $6 \mathbf{R}$ and 10R is small (Figure S32), and we must conclude that there is not enough spin density located in the central rings to consider them fully Baird aromatic. The positive charge at the conjugated rings of $6 R$ and $10 R$ in the lowest excited singlet state exhibits a systematic small increase with respect to the triplet state, with 21\% (6R) and 29\% (10R) Baird character.

Excitation induced aromaticity gain can be described in terms of the excited state electronic structure changes with respect to the ground state. Hückel and Baird aromaticity in the central ring could be achieved theoretically by adding to or withdrawing electrons from the ground state configuration, suggesting electron attachment and detachment processes, or by neutral excitations with CT character in which the pro-aromatic ring exchanges one (or more) electrons with other parts of the system. Here we tackle the latter by evaluating the CT character of low-lying states for the studied molecules. Quantification of electron density gain or loss in the central conjugated ring of molecules $\boldsymbol{n} \mathbf{R}(n=5,6,9$, and 10) indicates a very small displacement of electrons upon transition to $T_{1}$ and $S_{1}$ states (Table 1), in agreement with a HOMO-to-LUMO transition with the two frontier orbitals delocalized over the entire molecule 
(Figure 3). The computed charge differences between ground and excited state minima are within a rather small range, with electron density variations in the central ring smaller than 0.1 e in $\mathbf{5 R}, \mathbf{6 R}$, and $\mathbf{1 0 R}$, and about $0.12-0.13$ e increase of electrons in the 9-MR of $9 \mathbf{R}$. In most cases, there is an increase in the negative charge of the central ring when going from $\mathrm{S}_{0}$ to $\mathrm{T}_{1}$ and $\mathrm{S}_{1}$. Charge variations upon $\mathrm{S}_{0} \rightarrow \mathrm{S}_{1}$ transition at the Franck-Condon geometry, that is without taking into consideration structural relaxation on the excited state PES, are even smaller (Tables S20-S51).

Table 1. QTAIM charges (units are e) of the central ring unit for the ground $\left(\mathrm{S}_{0}\right)$ and the lowest excited triplet and singlet states at the excited state $\left(\mathrm{T}_{1}\right.$ and $\left.\mathrm{S}_{1}\right)$ geometries of $\boldsymbol{n} \mathbf{R}(n=5,6,9$, and 10) molecules computed at the B3LYP/6-311+G(d,p) level. $\Delta \mathrm{q}$ corresponds to the difference between the ring charges at the ground and excited state minima: $\Delta q\left(T_{1}\right)=q\left(T_{1}\right)-$ $\mathrm{q}\left(\mathrm{S}_{0}\right), \Delta \mathrm{q}\left(\mathrm{S}_{1}\right)=\mathrm{q}\left(\mathrm{S}_{1}\right)-\mathrm{q}\left(\mathrm{S}_{0}\right)$

\begin{tabular}{lcccc}
\hline state & $\mathbf{5 R}$ & $\mathbf{6 R}$ & $\mathbf{9 R}$ & $\mathbf{1 0 R}$ \\
\hline $\mathrm{S}_{0}$ & 0.066 & 0.445 & 0.134 & 0.551 \\
$\mathrm{~T}_{1}$ & 0.027 & 0.359 & 0.013 & 0.499 \\
$\mathrm{~S}_{1}$ & 0.120 & 0.420 & 0.006 & 0.589 \\
\hline$\Delta \mathrm{q}\left(\mathrm{T}_{1}\right)$ & -0.039 & -0.086 & -0.121 & -0.052 \\
$\Delta \mathrm{q}\left(\mathrm{S}_{1}\right)$ & 0.054 & -0.025 & -0.128 & 0.038 \\
\hline \hline
\end{tabular}

To further understand the $\mathrm{CT}$ character (or lack thereof) of the $\mathrm{T}_{1}$ and $\mathrm{S}_{1}$ states in relation to their potential Hückel and/or Baird aromaticity in the central conjugated ring, we evaluate the relative energy of the two potential electronic conformers (Hückel and Baird) of the $\boldsymbol{n} \mathbf{R}(n=5,6,9$, and 10$)$ series within the spin singlet and triplet manifolds. To that aim, we perform electronic structure calculations of the explicit Hückel and Baird configurations with 
two unpaired electrons, i.e., potentially associated to $T_{1}$ and $S_{1}$ states, by imposing the required charge (and spin) restrictions on the central ring and exocyclic groups, as indicated in Figure 7 for the triplet state, by means of constrained DFT calculations. ${ }^{51}$ Singlet and triplet Hückel configurations are more stable than the Baird forms in all four $\boldsymbol{n} \mathbf{R}$ systems. Moreover, the relative stabilization of the Hückel structure (Figure S41) is much larger in the two neutral molecules (6R and 10R, with the Hückel configuration 11.3 and $9.0 \mathrm{eV}$ more stable, respectively) than in the ionic systems (5R and $\mathbf{9 R}$, with the Hückel form favored by 2.5 and $4.4 \mathrm{eV}$, respectively), in good agreement with the previous analyses based on the charge, spin density, electron delocalization, and aromaticity indices in the central ring.
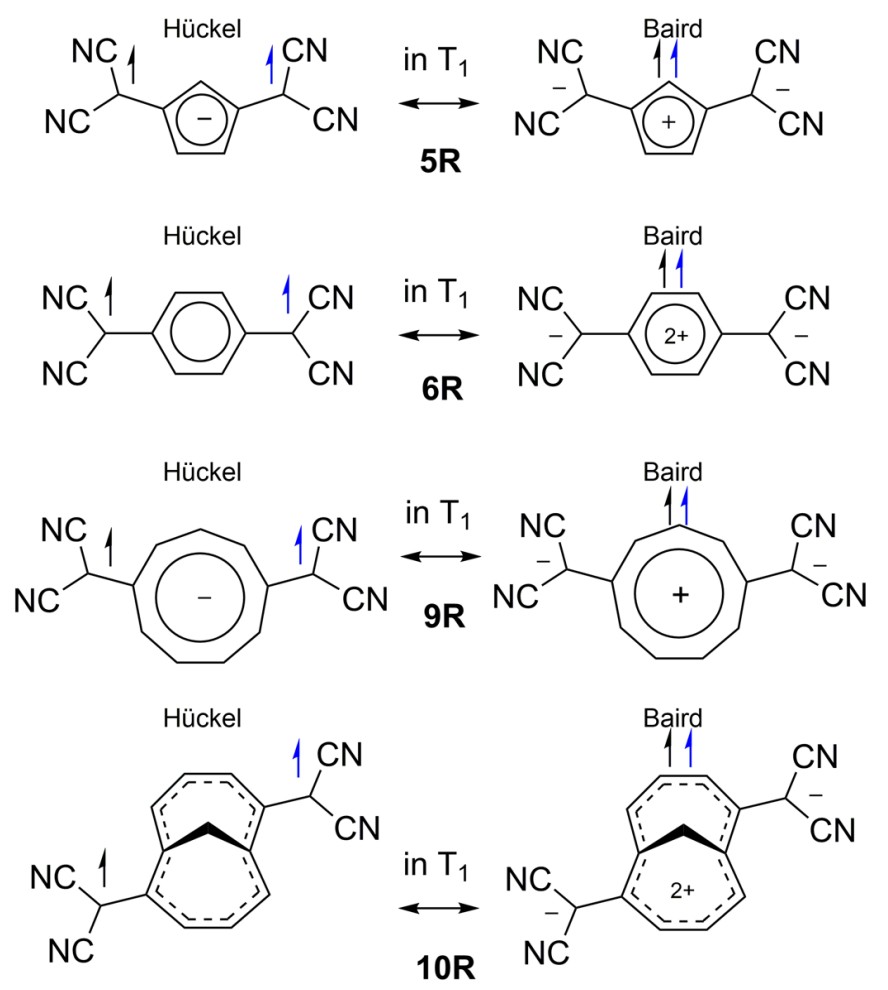

Figure 7. Hückel (left) and Baird (right) triplet state configurations of $\boldsymbol{n} \mathbf{R}(n=5,6,9$, and 10$)$ molecules.

Furthermore, we might approximate the $\mathrm{T}_{1}$ wave function as a mixing of Hückel $\left(\mathrm{T}_{\mathrm{H}}\right)$ and Baird $\left(\mathrm{T}_{\mathrm{B}}\right)$ triplet structures: 


$$
\Psi\left(T_{1}\right) \approx c_{H} \phi\left(T_{H}\right)+c_{B} \phi\left(T_{B}\right)
$$

where $\mathrm{c}_{\mathrm{H}}$ and $\mathrm{c}_{\mathrm{B}}$ amplitudes weight the Hückel and Baird contributions, respectively. The approximation in equation 1 allows us to describe the energy of $T_{1}$ as the lowest eigenvalue of a $2 \times 2$ model Hamiltonian written in the $\left(\mathrm{T}_{\mathrm{H}}, \mathrm{T}_{\mathrm{B}}\right)$ basis:

$$
\mathrm{H}=\left(\begin{array}{cc}
\varepsilon_{H} & \gamma \\
\gamma & \varepsilon_{B}
\end{array}\right)
$$

where $\varepsilon_{\mathrm{H}}$ and $\varepsilon_{\mathrm{B}}$ are the energies of the Hückel and Baird triplets, respectively, and $\gamma$ is the $T_{H} / T_{B}$ electronic coupling. Diagonalization of the Hamiltonian for the $T_{1}$ state in equation 2 can be used to obtain $\mathrm{c}_{\mathrm{H}}$ and $\mathrm{c}_{\mathrm{B}}$ amplitudes, and quantify the Baird (and Hückel) character of $\mathrm{T}_{1}$. The participations of the Baird structure in the lowest triplet calculated from $T_{1}, T_{H}$, and $T_{B}$ energies are shown in Figure 8c. The obtained results follow the same trend as the ones obtained from the analysis derived from QTAIM charges and spins (Figures 8a and 8b), although with smaller Baird amplitudes. Such energy-based analysis can also be performed for the lowest excited singlet, although in this case the Hückel/Baird deconvolution is more involved than for the triplet state, since in some cases the pristine closed-shell non-aromatic configuration (left structure in Figure 1) might also contribute to the $\mathrm{S}_{1}$ wave function.

From these results, we conclude that $\boldsymbol{n} \mathbf{R}(n=5,6,9$, and 10) compounds present central conjugated rings with mixed Hückel/Baird aromatic nature in the $T_{1}$ and $S_{1}$ states, in which the Baird aromatic character increases for anionic and small rings. The Baird aromatic character is slightly larger for $\mathrm{S}_{1}$ than for $\mathrm{T}_{1}$ states.

In the following, we consider a new set of compounds derived from the $\boldsymbol{n} \mathbf{R}$ series, in which we keep the central ring and change the exocyclic groups. Compounds $\boldsymbol{n R}$-T with $n=$ 5, 6, 9, and 10 contain the same central conjugated ring as in $\boldsymbol{n R}$, but the $\boldsymbol{n} \mathbf{R}-\mathbf{T}$ molecules accommodate a thiophene ring in each of the two exocyclic moieties. The motivation for this substitution is twofold: (i) to explore the impact of increasing the conjugation length of the 
exocyclic fragments, and (ii) to examine the recent experimental characterization of the 10R-T compound (TMTQ) in its singlet excited state. ${ }^{25}$

Compounds $\boldsymbol{n R} \mathbf{R}-\mathbf{T}$ present different structural conformers related to the relative orientation of the two thiophene rings. In all cases, the relative stability between cis and trans disposition of the thiophenes is rather small. In the following, all values will refer to the trans$\boldsymbol{n R} \mathbf{R}-\mathbf{T}$ systems. Results for the cis-nR-T species do not differ significantly and can be found in the Supporting Information.

The presence of the additional thiophenes increases the conjugation with respect to the $\boldsymbol{n} \mathbf{R}$ counterparts, with more delocalized HOMOs and LUMOs (Figure S5). As a result, the vertical and adiabatic energies to the lowest excited triplet and singlet states of $\boldsymbol{n R} \mathbf{R}-\mathbf{T}$ are systematically lower (Table S18). The larger conjugation of the two molecular arms stabilizes the two unpaired electrons in the $\mathrm{T}_{1}$ through radical delocalization, as shown by the spatial representation of the spin density (Figure S32). On the other hand, the total electron density on the central ring of $\boldsymbol{n R}-\mathbf{T}$ increases with respect to the corresponding counterparts without the thiophene rings ( $\boldsymbol{n} \mathbf{R}$ compounds), while the spin density on the central ring decreases. As a consequence, there is a substantial decrease of the Baird aromatic character in the $T_{1}$ and $\mathrm{S}_{1}$ states of $\boldsymbol{n R}-\mathbf{T}$ when compared to the neutral and anionic $\boldsymbol{n} \mathbf{R}$ molecules (Figures $8 \mathrm{a}$ and $8 \mathrm{~b}$ ). These results are consistent with the systematic decrease of $|\Delta F L U| / F L U$ values (Table S88) and the decrease of the Baird contribution derived from the energy difference between Hückel and Baird configurations (Figure 8c). 

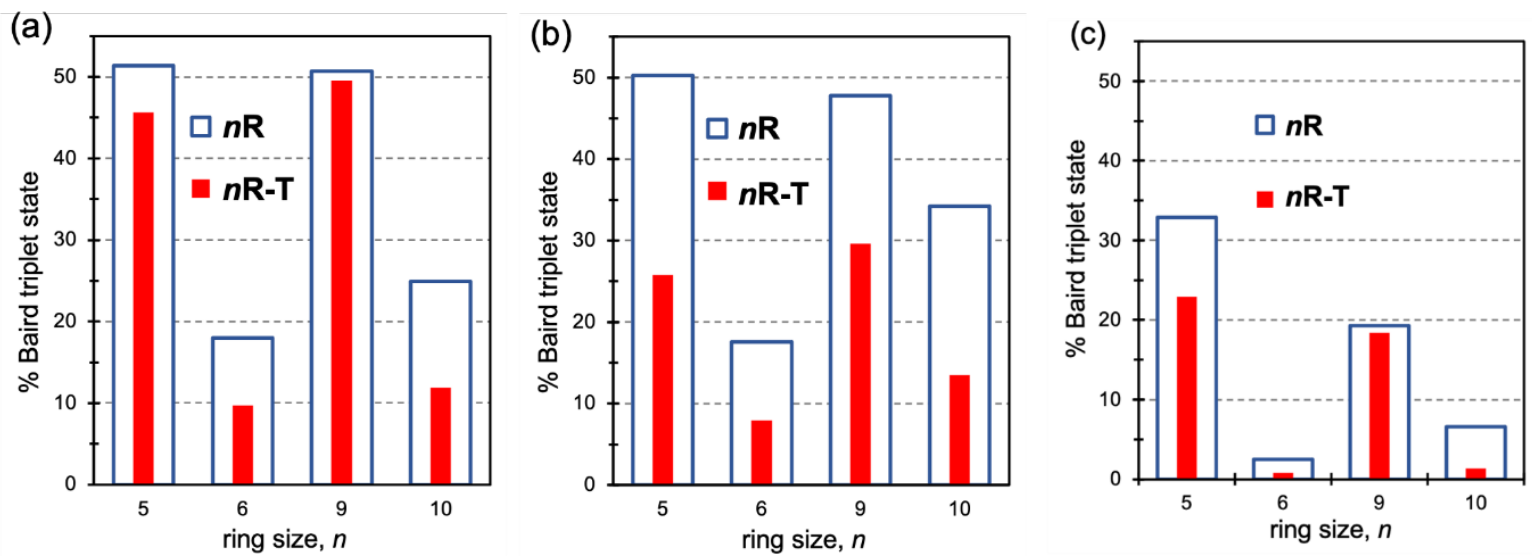

Figure 8. Baird contribution (in \%) to the $\mathrm{T}_{1}$ state based on (a) QTAIM charges, (b) spins, and (c) relative energies of the constrained Hückel and Baird forms in $\boldsymbol{n} \mathbf{R}$ and $\boldsymbol{n} \mathbf{R}-\mathbf{T}$ series with $n$ $=5,6,9$, and 10 .

The CT character of the $\mathrm{S}_{0} \rightarrow \mathrm{T}_{1}$ and $\mathrm{S}_{0} \rightarrow \mathrm{S}_{1}$ transition in $\boldsymbol{n R} \mathbf{R}-\mathbf{T}$ systems is not larger than in $\boldsymbol{n} \mathbf{R}$ (Tables S20-S38). These results seem to be in contradiction with recent experimental measurements, in particular for molecule 10R-T (TMTQ), for which photophysical properties were associated to a low-lying (singlet) excited state with two-electron CT character from the central 10-MR to the two exocyclic moieties. ${ }^{27}$ This point will be discussed in detail in the next section.

\section{Connection to experimental characterization}

As discussed in the previous section, computational characterization of the nature of the lowest excited singlet state of $\boldsymbol{n R}$ and $\boldsymbol{n R} \mathbf{R}-\mathbf{T}$ compounds (and of 10R-T in particular) indicates that the charge distribution in $\mathrm{S}_{1}$ barely changes with respect to $\mathrm{S}_{0}$. All charge analysis schemes employed in the present study indicate no charge displacement upon excitation (Table 1 and S20-S51), in agreement with a HOMO-to-LUMO transition with the two frontier orbitals 
delocalized over the entire molecule (Figures 3 and S5). Although these results seem to be in contradiction with the experimental data, in the following we argue that they are perfectly compatible. Conversely, we state that the previous interpretation ${ }^{27}$ of the excited state character and aromaticity in 10R-T needs to be revised.

\subsection{Shift of the $C N$ stretching band}

Infrared (IR) spectroscopy measurements on the relative position of the nitrile stretching band in conjugated systems with terminal dicyanomethylene have been used as experimental fingerprint of the $\mathrm{CT}$ character of electronic transitions in multiple occasions, since the increase of negative charge on the $\mathrm{C}(\mathrm{CN})_{2}$ unit produces a redshift of the $\mathrm{CN}$ stretching band. ${ }^{52-56}$ On the other hand, DFT calculations by Jorner and collaborators ${ }^{26}$ have suggested that the displacement of the nitrile vibration frequency towards lower wavenumbers might also be caused by radical delocalization. The radical delocalization driven frequency shift has been speculated in a series of quinoidal oligothiophenes carrying a dicyanomethylene group at both terminal positions,${ }^{57}$ in which there is a redshift of the IR absorption frequency with the size of the number of thiophene rings.

To clarify the potential source of the vibrational shift in dicyanomethylenes, we perform benchmarking frequency calculations on one-carbon and three-carbon model systems which are either of neutral saturated, anionic and radical character (Figure 9). To compare the effect of charge vs. radical delocalization on nitrile frequencies, we quantify the displacement of nitrile vibrations for the anionic and radical forms with respect to the neutral molecules. 

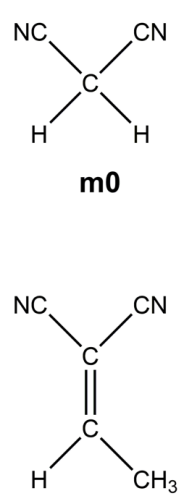

e0
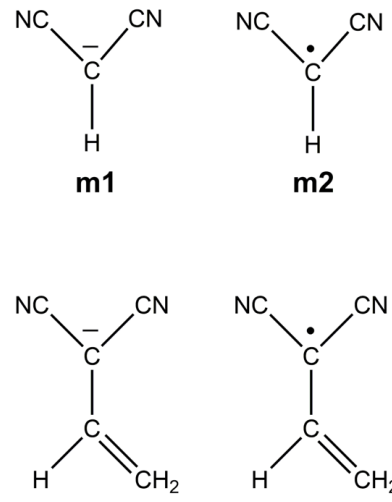

e1

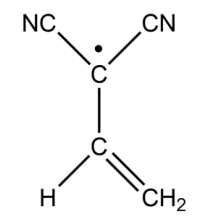

e2

Figure 9. Dicyanomethane (m0), dicyanomethyl anion (m1) and dicyanomethyl radical (m2) (top), and 1,1-dicyanopropene (e0, bottom), 1,1-dicyanoallyl anion (e1), and 1,1-dicyanoallyl radical (e2).

Table 2. Average shift of the $\mathrm{CN}$ vibration $\left(\right.$ in $\left.\mathrm{cm}^{-1}\right)$ for the anionic ( $\mathbf{m} \mathbf{1}$ and $\left.\mathbf{e} \mathbf{1}\right)$ and radical ( $\mathbf{m} \mathbf{2}$ and $\mathbf{e 2}$ ) forms with respect to the neutral species ( $\mathbf{m} \mathbf{0}$ and $\mathbf{e} \mathbf{0})$ for the model compounds in Figure 9 computed at the CCSD and B3LYP levels with the 6-311+G(d) basis set. ${ }^{a}$

\begin{tabular}{|c|c|c|}
\hline species & CCSD & B3LYP \\
\hline m1 & -143 & -166 \\
\hline $\mathbf{m} 2$ & -149 & -179 \\
\hline e1 & -104 & -111 \\
\hline e2 & -57 & -75 \\
\hline
\end{tabular}

Both charged and radical systems induce a redshift on the computed $\mathrm{CN}$ stretching (Table 2). Moreover, the shift decreases with the conjugation of the system. Dicyanoethyl has the possibility to delocalize the negative charge (e1) and the unpaired electron (e2), reducing the charge and radical density on the $\mathrm{C}$ atom with two cyano substituents, respectively. As a result, the absolute shift of $\mathrm{CN}$ frequency is smaller than in diacyanomethane. Although the negative charge density induces stronger shifts than the unpaired electron density, we might extrapolate that for larger conjugated systems both effects will be less intense than in the model 
systems due to lower charge/radical densities (larger delocalization), and their differences will diminish. Therefore, we conclude that the excited state redshift in $v(\mathrm{CN})$ cannot be unequivocally associated to a CT-induced increase of the electron density on the dicyanomethyl anion.

Interestingly, B3LYP displacements agree with CCSD results. Hence, we have calculated ground and excited state B3LYP frequencies for the entire family of studied systems. Our calculations predict a redshift of the excited $v(\mathrm{CN})$ with respect to the ground state frequency in all $\boldsymbol{n R}$ and $\boldsymbol{n R} \mathbf{R}-\mathbf{T}$ compounds, which must be attributed to the radical delocalization effect (and not to a CT character of $\mathrm{S}_{1}$, Table S53). Moreover, the displacement towards lower frequencies is larger in $\boldsymbol{n} \mathbf{R}\left(24 \mathrm{~cm}^{-1}\right.$ in average $)$ than for the $\boldsymbol{n} \mathbf{R}-\mathbf{T}$ series $\left(11 \mathrm{~cm}^{-1}\right.$ in average), which can be related to the larger delocalization of the unpaired electrons in $\mathrm{S}_{1}$ provided by the thiophene rings (radical delocalization effect). Concretely, the $S_{0}$ to $S_{1}$ redshift in compound 10R-T (TMTQ) is computed at $16 \mathrm{~cm}^{-1}$ (experimentally measured at $\left.45 \mathrm{~cm}^{-1}\right){ }^{27}$ The obtained $v(\mathrm{CN})$ redshifts for the triplet state follow the same trends as in $\mathrm{S}_{1}$, although the shifts are slightly larger than in $\mathrm{S}_{1}$ (Table S53).

\subsection{Photophysical dependence on the solvent polarity}

The excited state dependence with the solvent polarity can be rationalized in terms of the different (permanent) dipole moment in the ground and excited states, and by different stabilization of the $\mathrm{S}_{1}$ state with changes in the solvent polarity. In the following, we discuss the dependency of the $\mathrm{S}_{1}$ state properties on the solvent's dielectric constant. Here we focus on 10R-T molecule since the dependence of its photophysical behavior with the polarity of the solvent has been experimentally described. Results for other compounds can be found in the Supporting Information. 
The dipole moments of 10R-T in $S_{0}$ and $S_{1}$ are perpendicularly oriented with respect to the M10A moiety (Figure 10) and increase with the solvent polarity (Table 3). Importantly, despite the lack of CT character of $\mathrm{S}_{1}$ state in 10R-T, there is a sizeable increase of the magnitude of the molecular dipole moment upon $\mathrm{S}_{0} \rightarrow \mathrm{S}_{1}$ transition, which might explain the dependence of excited state dynamics with the solvent polarity experimentally observed. ${ }^{27}$ Results obtained with different energy functionals are all in quantitative agreement with B3LYP (Tables S1 and S2).

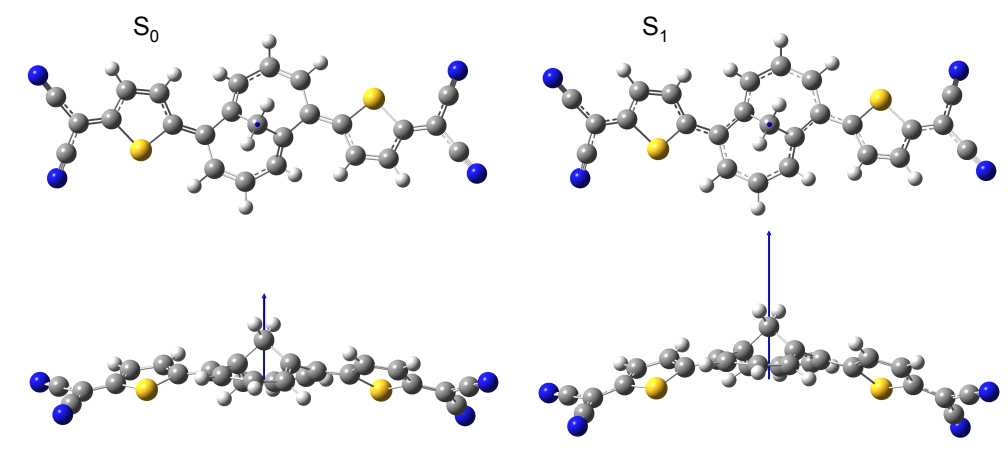

Figure 10. Permanent dipole moments (blue arrows) for the ground (left) and first excited singlet (right) states of 10R-T computed at the B3LYP/6-311+G(d,p) level.

Moreover, calculations of the $\mathrm{S}_{1}$ excitation in solution with two solvents with very different dielectric constants, i.e., toluene $(\varepsilon=2.38)$ and nitromethane $(\varepsilon=35.87)$, indicate an increase in the difference between $\mathrm{S}_{0}$ and $\mathrm{S}_{1}$ dipole moments $(\Delta \mu)$ and a decrease of the excitation energies with the solvent polarity (Table 3). All in all, these results reaffirm the dependence of the excited state decay with the polarity of the solvent without the need for strong CT character in the electronic transition. 
Table 3. Permanent dipole moments (in Debye) for the ground and first excited singlet states and their difference $(\Delta \mu)$, and $\mathrm{S}_{1}$ adiabatic energy $\left(\Delta E\left(\mathrm{~S}_{1}\right)\right.$ in $\left.\mathrm{eV}\right)$ of 10R-T computed at the B3LYP/6-311+G(d,p) level in toluene and nitromethane. Orientation of the dipole moments for the two states are shown in Figure 10.

\begin{tabular}{lcccc}
\hline \hline solvent & $\boldsymbol{\mu}\left(\mathbf{S}_{\mathbf{0}}\right)$ & $\boldsymbol{\mu}\left(\mathbf{S}_{\mathbf{1}}\right)$ & $\Delta \mu$ & $\Delta \boldsymbol{E}\left(\mathbf{S}_{\mathbf{1}}\right)$ \\
\hline toluene & 4.526 & 7.026 & 2.500 & 1.42 \\
nitromethane & 5.664 & 8.521 & 2.857 & 1.19 \\
\hline \hline
\end{tabular}

\section{Searching for systems with high Baird-aromatic character}

\subsection{Cyclopentadienylidene and cyclopropenylidene substitution}

In this section, we explore the potential increase of Baird-aromaticity by means of cyclopentadienylidene and cyclopropenylidene substitution at the five- and six-membered conjugated rings (5R-5a-c, 6R-5a-c, and 6R-3a-c in Figure 3). Such substitution provides for terminal (exocyclic) units which themselves can be Hückel-aromatic.

The $\mathrm{T}_{1}$ state of compounds 5R-5a and 6R-5a, both having cyclopentadienylidene rings, can display push-pull captodative aromaticity. ${ }^{58}$ For this state, QTAIM charges $(-0.225$ vs. 0.102$)$, spin densities (0.839 vs. 0.325$)$, and $|\Delta F L U| / F L U$ values $(2.192$ vs. 0.642$)$ in the central rings and the relative Hückel/Baird triplet stability (Figure S41) indicate a much large Baird aromatic character in $\mathbf{5 R - 5 a}$ than in 6R-5a. The same situation was found when comparing $\mathbf{5 R}$ and $\mathbf{6 R}$. The Baird aromatic character in the 5-MR of $\mathbf{5 R}$ in the $\mathrm{T}_{1}$ state is larger than that in 5R-5a. The same trend is observed for the $S_{1}$ state, that is, slightly weaker Baird character of $\mathbf{5 R - 5 a}$ when compared to $\mathbf{5 R}$, although the central rings in the $\mathrm{S}_{1}$ state exhibit slightly higher Baird aromatic character, e.g., less electron density in the ring. This result, 5R- 
5a $<$ 5R of Baird character, is in contradiction with a two-electron transfer from the central ring, which would lead to two external Hückel aromatic cyclopentadienyl anionic rings and one Baird aromatic cyclopentadienyl cationic ring in the middle. In fact, the $\mathrm{T}_{1}$ state in $\mathbf{5 R - 5 a}$ is obtained as the delocalization of the two unpaired electrons over the three 5-MRs (Figure 11), resulting in partial Baird-aromaticity. Substituting 5R-5a with methyl groups to impose steric congestion at the planar structure (5R-5b), forcing the three rings out of the same plane, results in a minor reduction of the negative charge and spin density in the central ring. On the other hand, a more significant increase of $\sim 0.26$ e is observed in the spin density of the central ring of 5R-5c, thanks to the electron-donating groups (EDG) attached to the central 5-MR and the electron-withdrawing groups (EWG) at the exocyclic 5-MRs. Interestingly, constrained Hückel/Baird calculations of $\mathbf{5 R - 5 a}$ produce very similar results to those obtained for $\mathbf{5 R}$, while the singlet and triplet Baird configurations become slightly more stable than the Hückel forms in $\mathbf{5 R - 5 b}$ and $\mathbf{5 R - 5 c}$.

The same substitution series produces rather different results in the 6-MR counterparts (6R-5a-c). The three conjugated rings are coplanar in 6R-5a with minor spin density on the central 6-MR (Figure 11). Steric hindrance in 6R-5b breaks the molecular planarity with orthogonal disposition of the central and side rings in the triplet state, with the two unpaired electrons localized on the two external cyclopentadienylidene units. Hence, the central ring has a very strong Hückel aromatic character. Substitution with EWG and EDG groups in $\mathbf{6 R - 5 c}$ does not change the nature of the triplet state and the central ring remains a local Hückel singlet. It is worth noting that, despite the low Baird character of their central rings, $6 \mathbf{R}-5 \mathrm{~b}$ and $\mathbf{6 R - 5 c}$ are the only studied compounds that have the triplet state below the Kohn-Sham singlet and degenerated with respect to the broken symmetry open-shell singlet solution (Table S18). 


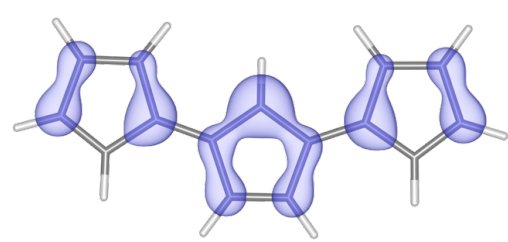

${ }^{3} \mathbf{5 R}-5 \mathrm{a}$

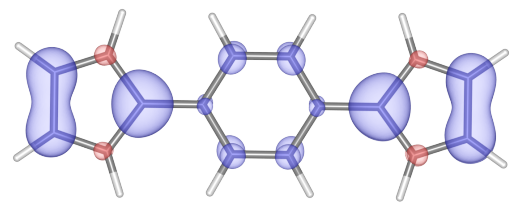

${ }^{3} 6 \mathbf{R}-5 \mathbf{a}$

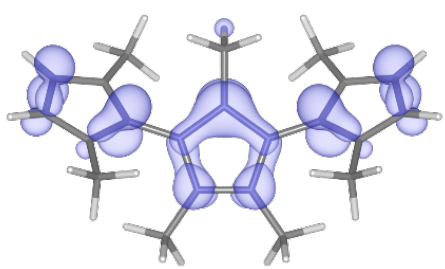

${ }^{3} \mathbf{5 R - 5 b}$

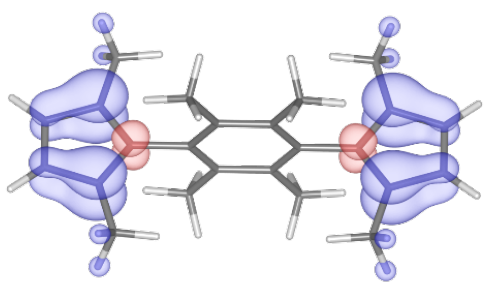

${ }^{3} 6 \mathbf{R - 5 b}$

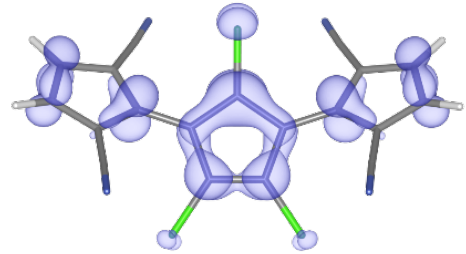

${ }^{3}$ 5R-5c

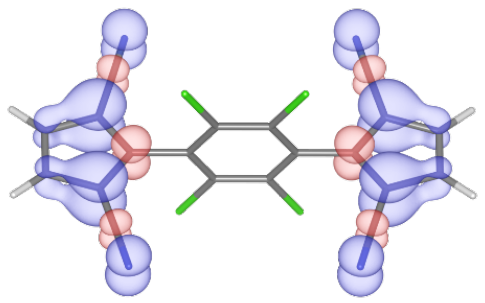

${ }^{3} 6 \mathrm{R}-5 \mathrm{c}$

Figure 11. Spin density for the $T_{1}$ state of 5R-5a-c (top) and 6R-6a-c (bottom) compounds computed at the B3LYP/6-311+G(d,p) level. The isodensity shown corresponds to a value of $0.005 \mathrm{e}-/ \mathrm{bohr}^{3}$. The positive and negative spin density surfaces are represented in blue and red, respectively.

Results on 6R-5a-c clearly show that the symmetric functionalization of the benzene ring with cyclopentadienylidene is not able to generate significant Baird aromaticity in the central ring. Hence, in order to induce Baird character to the central 6-MR, we consider next the cyclopropenylidene substitution (6R-3a-c). For the three compounds, we observe a sizeable triplet state spin density of about 0.5 e on the central ring, which would suggest an increase of the Baird aromatic character $(c a .25 \%)$ in $6 \mathbf{R - 3 a - c}$ with respect to 6R-5a-c. The order of Baird aromaticity in the central ring is $6 \mathbf{R - 3 b}>\mathbf{6 R - 3 c}>\mathbf{6 R - 3 a}$. Similar percentage (and order) of Baird aromaticity is given by the $|\Delta \mathrm{FLU}| / \mathrm{FLU}$ values found in the range 1.124 to 1.678 when compared to the value of the reference triplet Baird ring $\mathrm{C}_{6} \mathrm{H}_{6}{ }^{2+}$ (4.693, Table S105). The relative stability of Hückel/Baird configurations indicate a strong preference for the Hückel form in $\mathbf{6 R - 3 a}$, whereas in $\mathbf{6 R - 3 b - c}$ the gap between the two configurations is much smaller (Figure S41). A close examination of the spin density distribution in the triplet state of 
cyclopropenylidene substituted 6-MR reveals that the two unpaired electrons mainly localize on the external atoms with delocalization towards the 6-MR moiety (Figure S32). This picture becomes clear in $\mathbf{6 R - 3 \mathbf { c }}$, for which the excess of $\alpha$ spin density is perpendicular to the $\pi$-system of the central ring, and should be associated with spin delocalization from the external rings rather than a Baird aromatic character of the central ring.

\subsection{Four-membered heterocycles}

In this case we explore a completely different strategy in the quest for excited state Baird aromaticity, that is the use of 4-membered heterocycles with cyclopentadienylidene moieties (compounds 4RN-5 and 4RO-5). Results based on charges, spin densities, and $|\Delta \mathrm{FLU}| / \mathrm{FLU}$ values of the $\mathrm{T}_{1}$ state do not allow us to conclude which one has the largest Baird aromatic character. Whereas $|\Delta \mathrm{FLU}| / \mathrm{FLU}$ in the central ring is 1.845 in $\mathbf{4 R O}-\mathbf{5}$ and 0.870 in 4RN-5, spin densities indicate that contribution of Baird aromaticity is similar in both systems (21-23\%), and electronic charges give more Baird character to $4 \mathbf{R N}-5$ with 0.045 e $\left(\mathrm{S}_{1}\right)$ and 0.025 e $\left(\mathrm{T}_{1}\right)$ than to 4 RO-5 with -0.203 e $\left(\mathrm{S}_{1}\right)$ and -0.231 e $\left(\mathrm{T}_{1}\right)$. Moreover, Hückel and Baird constrained energies indicate strong preference for the Hückel configuration in the singlet and triplet states of $\mathbf{4 R N - 5}$ and $\mathbf{4 R O}-5$. Hence, these results make us conclude that, although the central ring in $4 \mathbf{R N}-5$ and $\mathbf{4 R O}-5$ is more Baird aromatic than the 6-MR of $6 \mathbf{R - 5 a}$, the Baird character is mild at most, and definitely smaller than in the 5-MR of 5R-5a.

\subsection{Protonated systems}

As shown above, the Baird aromatic character of the central ring in the $\mathrm{T}_{1}$ and $\mathrm{S}_{1}$ states increases for species having anionic and small central rings as well as small exocyclic groups that do not allow for a large electronic delocalization. We now investigate whether the Baird character can be enhanced by protonation. Concretely, we explore the protonation of two cyano groups in $\mathbf{5 R}\left(\mathbf{5 R - 2} \mathrm{H}^{+}\right), 6 \mathbf{R}\left(\mathbf{6 R - 2} \mathbf{H}^{+}\right)$, and $10\left(\mathbf{1 0 - 2} \mathbf{H}^{+}\right)$, and four cyano groups in $\mathbf{5 R}-$ 
$\mathbf{4} \mathbf{H}^{+}$. We must stress that the protonated compounds investigated here do not necessarily correspond to the most stable molecular species, and have solely been introduced to establish general guidelines in the quest for systems with higher Baird aromaticity. For instance, one can expect that the first protonation of $\mathbf{5 R}$ will take place at the negatively charged 5-MR rather than at the cyano groups. Thus, these systems reveal to what extremes one need to go to in order to reach high Baird aromatic character in molecules of Hückel/Baird hybrid type.

The (unprotonated) $\mathbf{5 R}$ compound exhibits one unpaired electron in the central ring of the $\mathrm{T}_{1}$ state, with a local spin density of $1.006 \mathrm{e}$. Protonation of two $\left(\mathbf{5 R}-\mathbf{2} \mathbf{H}^{+}\right)$and four $\left(\mathbf{5 R}-4 \mathrm{H}^{+}\right)$cyano groups increases the spin density at the 5-MR to 1.365 e and $1.567 \mathrm{e}$, respectively. Hence, we move from ca. $50 \%$ of Baird aromatic character in $\mathbf{5} \mathbf{R}$ to $68 \%$ in $\mathbf{5 R}$ $\mathbf{2} \mathbf{H}^{+}$and to $78 \%$ in $\mathbf{5 R - 4} \mathbf{H}^{+}$, in agreement with a ring charge rather close to the ideal Baird value ( $\sim 0.7$ e) for a cationic ring. The strong excited state Baird character in $\mathbf{5} \mathbf{R}-\mathbf{2} \mathbf{H}^{+}$and $\mathbf{5} \mathbf{R}-\mathbf{4} \mathbf{H}^{+}$is supported by the (triplet and singlet) lower energy obtained for the Baird configurations with respect to the Hückel counterparts $\left(\varepsilon_{\mathrm{B}}<\varepsilon_{\mathrm{H}}\right)$. Application of the approximation in equations 1 and 2 reveals Baird aromatic characters of $69 \%$ (triplet) and $66 \%$ (singlet) in $\mathbf{5 R - 2} \mathbf{H}^{+}$, and of $86 \%$ (triplet) and $82 \%$ (singlet) in $\mathbf{5 R - 4} \mathbf{H}^{+}$, in very good agreement with the quantification derived from charge and spin analysis of $T_{1}$. Double protonation in $\mathbf{6 R}$ and $\mathbf{1 0 R}$ also results in a significant increase of about $5-15 \%$ in the Baird aromatic character of the central ring.

\subsection{Seven-membered electron-deficient central rings}

Next, instead of trying to pull electrons out of a non-aromatic $\pi$-conjugated ring like in many of the systems explored so far, we envisage the possibility of reaching excited state Baird aromaticity by injecting electrons into a conjugated ring. ${ }^{59}$ To that aim, we design two compounds with a cationic 7-MR with exocyclic carbons substituted with EDG, i.e., 7Ra and $7 \mathbf{R b}$. 
The 7-MR ring in $S_{1}$ and $T_{1}$ states of $7 \mathbf{R a}$ and $\mathbf{7} \mathbf{R b}$ is effectively neutral, suggesting equal mixing of Hückel and Baird character. The $T_{1}$ spin density is notably located on the central ring (Figure 12), accounting for $\sim 1.5$ e delocalized on the 7-MR for both molecules. Evaluation of the relative stability of Hückel and Baird configurations confirm the strong Baird character with contributions estimated to be $57 \%$ (triplet and singlet) in $\mathbf{7 R a}$ and $68 \%$ (triplet) and 67\% (singlet) in $\mathbf{7} \mathbf{R b}$. Therefore, the combination of an electron deficient conjugated ring with electron-donor exocyclic substitution seems a good strategy towards Baird aromaticity.

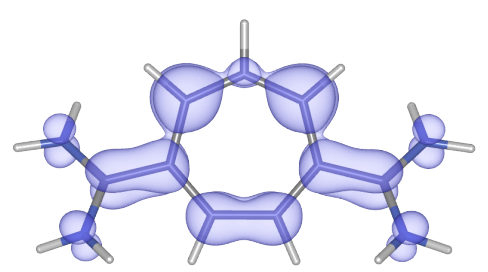

${ }^{3} 7 \mathbf{R a}$

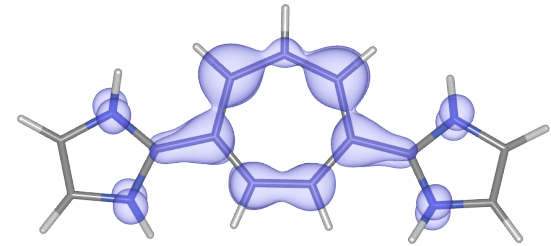

${ }^{3} 7 \mathbf{R b}$

Figure 12. Spin density for the $T_{1}$ state of $7 \mathbf{R a}$ (left) and $\mathbf{7} \mathbf{R b}$ (right) compounds computed at the B3LYP/6-311+G(d,p) level. The isodensity contour shown corresponds to a value of 0.005 $\mathrm{e}^{-} /$bohr $^{3}$. The positive and negative spin density surfaces are represented in blue and red, respectively.

\section{General picture and conclusions}

The results from this study stress that characterization of Baird aromaticity needs to be carried out with care and that the labelling of a conjugated ring as Baird aromatic requires a detailed analysis of the excited state electronic structure. Probably a safe procedure is the one presented here, in which several parameters and computational tools are combined, namely ring charge, ring spin density, DIs, aromaticity indices with separated $\alpha$ and $\beta$ contributions, and the newly introduced energy-based analysis of the Hückel and Baird configurations. 
The Baird aromaticity of the studied systems can be related to the (local) charge and spin in the central ring. While ring charge and spin might be good indicators of the Baird character of electronic states, they do not univocally correspond to a specific type of aromaticity. In other words, it is not possible (in general) to establish a one-to-one map between charge (or spin) with the amount of Baird aromaticity. Therefore, here we take a conservative approach for the quantification of the Baird character of $T_{1}$ and $S_{1}$ states by considering the lowest Baird percentage derived from charge and spin analyses (Figure 13). Quantification of Baird aromaticity in the excited singlet state has been obtained from $\mathrm{S}_{1}$ ring charges corrected by the charge/spin differences in $\mathrm{T}_{1}$ (equations $\mathrm{S} 8-\mathrm{S} 11$ ). The use of relative energies between constrained calculations of Hückel and Baird configurations for the systems investigated is, in general, in good agreement with the quantification of Baird character from charge/spin measurements.

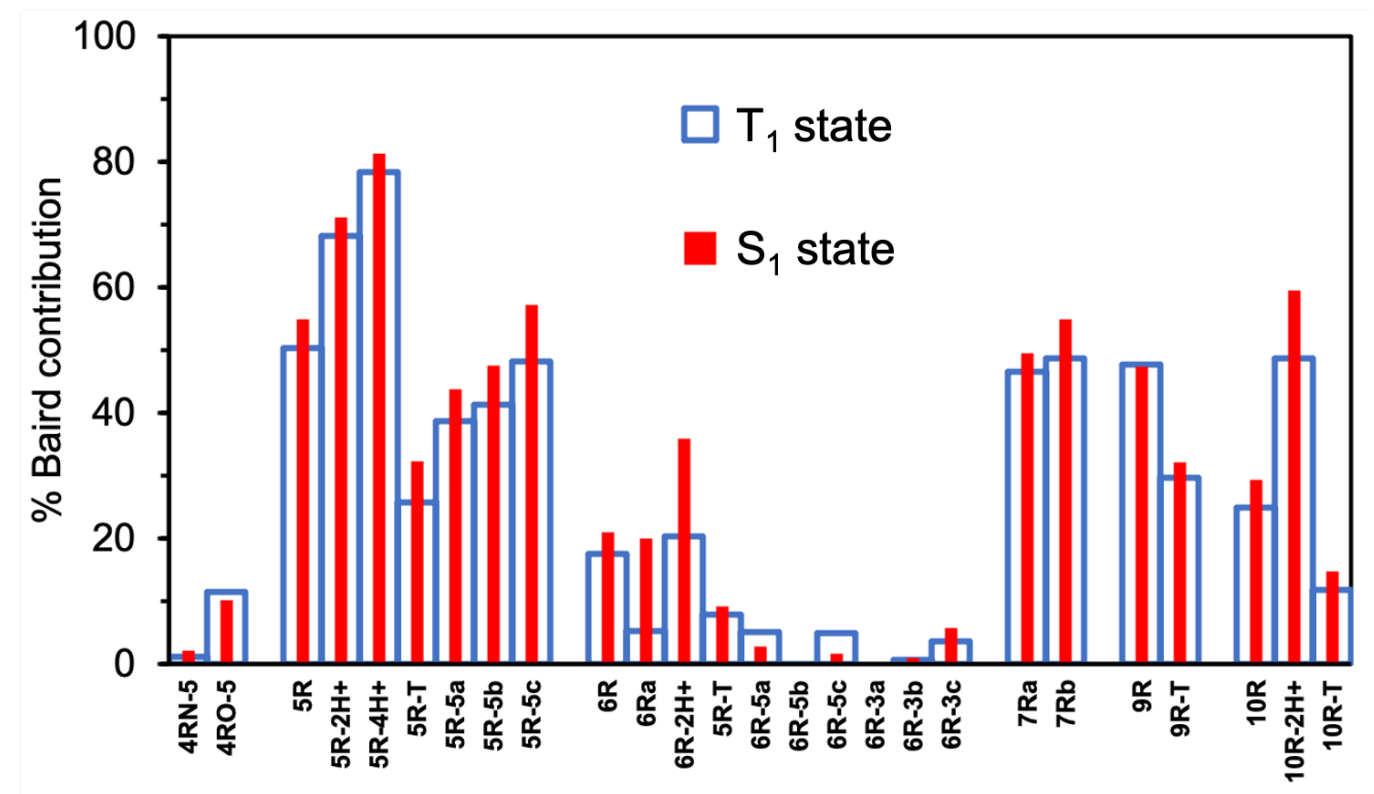

Figure 13. Baird contribution (in \%) based on QTAIM charges and spins for the $\mathrm{T}_{1}$ and $\mathrm{S}_{1}$ states in all studied systems. 
Generation of excited state Baird aromaticity in symmetrically substituted conjugated rings appears rather difficult. High Baird aromatic character $(>50 \%)$ in these systems is achieved in molecules with anionic and small central rings with EDG as substituents and small exocyclic groups substituted with EWG. Alternatively, the combination of an electron deficient conjugated ring with electron-donor exocyclic substitution also seems a good strategy

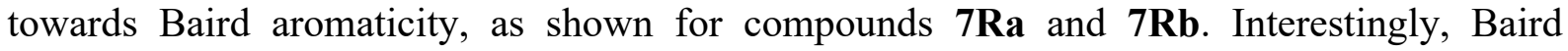
aromaticity in the excited singlet state is typically larger than in the triplet state (mostly ca. 5$10 \%$ larger and never more than 20\%, see Fig. 13), especially for those cases with appreciable Baird character $(>10 \%)$.

Overall, our analysis indicates that the symmetric substitution of conjugated rings favors the presence of low-energy excited states with weak (or modest at most) CT character, i.e., with small changes in the number of $\pi$-electrons in the central conjugated ring. The coplanarity between the central ring and the two side groups symmetrically arranged facilitates the hole and electron delocalization of the transition, resulting in no charge separation. In general, low-lying excitations of symmetrically substituted conjugated rings hold very weak CT character. In light of the present results, previously assigned excited state Baird aromaticity in symmetrically substituted rings, in particular for compound 10R-T, based on the allegedly strong CT character of the electronic transition needs to be revised. Based on extensive computational results, we have presented an alternative interpretation of the experimental measurements, i.e., the shift in the CN IR stretching band and dependence of excited state decay on the solvent polarity, which does not require charge separation upon excitation and seems, in our opinion, much more feasible. 


\section{Acknowledgements}

The authors thank the Ministerio de Economía y Competitividad (MINECO) of Spain (projects PGC2018-097722-B-I00， CTQ2017-85341-P， PGC2018-098212-B-C21， EUR2019-103825， and PID2019-109555GB-I00), the Generalitat de Catalunya (project 2017SGR39 and the ICREA Academia prize 2019 awarded to A.P.), the Eusko Jaurlaritza/Basque Government (projects PIBA19-0004, IT1254-19, and 2019-CIEN-000092-01), and the Swedish Research Council (grant 2019-05618). S.E. thanks Universitat de Girona and Donostia International Physics Center (DIPC) for an IFUdG2019 PhD fellowship. A.P. is a Serra Húnter Fellow. The authors are thankful for the technical and human support provided by the Donostia International Physics Center (DIPC) Computer Center.

\section{ASSOCIATED CONTENTS}

\section{Supporting Information}

Computational details, functional and solvent dependence, relative energies of $\mathrm{S}_{0}, \mathrm{~T}_{1}$ and $\mathrm{S}_{1}$ states, molecular orbitals, vertical excitations, structural analysis, charge and spin densities, $\mathrm{CN}$ vibrational frequencies, delocalization and aromaticity indices, C-DFT calculations are given in the supp_info.pdf file. 


\section{References}

1. Klan, P.; Wirz, J., Photochemistry of Organic Compounds: From Concepts to Practice. Wiley: Weinheim, 2009.

2. Meyer, T. J., Photochemistry of metal coordination complexes: metal to ligand charge transfer excited states. Pure \& Appl. Chem. 1986, 58, 1193-1206.

3. Endicott, J. F., Charge-Transfer Excited States of Transition Metal Complexes. In Electron Transfer in Chemistry, Balzani, V., Ed. Wiley-VCH: Weinheim, 2001; pp 238-270.

4. Sasaki, S.; Drummen, G. P. C.; Konishi, G.-i., Recent advances in twisted intramolecular charge transfer (TICT) fluorescence and related phenomena in materials chemistry. J. Mat. Chem. C 2016, 4, 2731-2743.

5. $\quad$ Shi, X.; Quintero, E.; Lee, S.; Jing, L.; Herng, T. S.; Zheng, B.; Huang, K.-W.; López Navarrete, J. T.; Ding, J.; Kim, D.; Casado, J.; Chi, C., Benzo-thia-fused [n] thienoacenequinodimethanes with small to moderate diradical characters: the role of pro-aromaticity versus anti-aromaticity. Chem. Sci. 2016, 7, 3036-3046.

6. $\quad$ Escayola, S.; Callís, M.; Poater, A.; Solà, M., Effect of Exocyclic Substituents and $\pi-$ System Length on the Electronic Structure of Chichibabin Diradical(oid)s. ACS Omega 2019, 4, 10845 10853.

7. Inouchi, T.; Nakashima, T.; Kawai, T., Charge Transfer Emission of T-Shaped $\pi$ Conjugated Molecules: Impact of Quinoid Character on the Excited State Properties. J. Phys. Chem. A 2014, 118, 2591-2598.

8. Baird, N. C., Quantum organic photochemistry. II. Resonance and aromaticity in the lowest ${ }^{3} \pi \pi^{*}$ state of cyclic hydrocarbons. J. Am. Chem. Soc. 1972, 94, 4941-4948.

9. $\quad$ Rosenberg, M.; Dahlstrand, C.; Kilså, K.; Ottosson, H., Excited State Aromaticity and Antiaromaticity: Opportunities for Photophysical and Photochemical Rationalizations. Chem. Rev. 2014, 114, 5379-5425.

10. Ottosson, H., Organic photochemistry: Exciting excited-state aromaticity. Nature Chem. 2012, 4, 969-971.

11. Papadakis, R.; Ottosson, H., The excited state antiaromatic benzene ring: a molecular $\mathrm{Mr}$ Hyde? Chem. Soc. Rev. 2015, 44, 6472-6493.

12. Oh, J.; Sung, Y. M.; Hong, Y.; Kim, D., Spectroscopic Diagnosis of Excited-State Aromaticity: Capturing Electronic Structures and Conformations upon Aromaticity Reversal. Acc. Chem. Res. 2018, 51, 1349-1358.

13. Durbeej, B.; Wang, J.; Oruganti, B., Molecular Photoswitching Aided by Excited-State Aromaticity. ChemPlusChem 2018, 83, 958-967.

14. Liu, C.; Ni, Y.; Lu, X.; Li, G.; Wu, J., Global Aromaticity in Macrocyclic Polyradicaloids: Hückel's Rule or Baird's Rule? Acc. Chem. Res. 2019, 52, 2309-2321.

15. Karadakov, P. B., Ground- and Excited-State Aromaticity and Antiaromaticity in Benzene and Cyclobutadiene. J. Phys. Chem. A 2008, 112, 7303-7309.

16. Karadakov, P. B., Aromaticity and Antiaromaticity in the Low-Lying Electronic States of Cyclooctatetraene. J. Phys. Chem. A 2008, 112, 12707-12713.

17. Feixas, F.; Vandenbussche, J.; Bultinck, P.; Matito, E.; Solà, M., Electron delocalization and aromaticity in low-lying excited states of archetypal organic compounds. Phys. Chem. Chem. Phys. 2011, 13, 20690-20703.

18. Karadakov, P. B.; Hearnshaw, P.; Horner, K. E., Magnetic Shielding, Aromaticity, Antiaromaticity, and Bonding in the Low-Lying Electronic States of Benzene and Cyclobutadiene. $J$. Org. Chem. 2016, 81, 11346-11352.

19. Rosenberg, M.; Ottosson, H.; Kilså, K., Influence of excited state aromaticity in the lowest excited singlet states of fulvene derivatives. Phys. Chem. Chem. Phys. 2011, 13, 12912-12919.

20. Ueda, M.; Jorner, K.; Sung, Y. M.; Mori, T.; Xiao, Q.; Kim, D.; Ottosson, H.; Aida, T.; Itoh, Y., Energetics of Baird aromaticity supported by inversion of photoexcited chiral [4n]annulene derivatives. Nature Commun. 2017, 8, 346. 
21.

Kotani, R.; Liu, L.; Kumar, P.; Kuramochi, H.; Tahara, T.; Liu, P.; Osuka, A.; Karadakov, P. B.; Saito, S., Controlling the $\mathrm{S}_{1}$ Energy Profile by Tuning Excited-State Aromaticity. J. Am. Chem. Soc. 2020, 142, 14985-14992.

22. Shukla, D.; Wan, P., Evidence for a planar cyclically conjugated 8.pi. system in the excited state: large Stokes shift observed for dibenz[b,f]oxepin fluorescence. J. Am. Chem. Soc. 1993, $115,2990-2991$.

23. Toldo, J.; El Bakouri, O.; Solà, M.; Norrby, P.-O.; Ottosson, H., Is Excited-State Aromaticity a Driving Force for Planarization of Dibenzannelated $8 \pi$-Electron Heterocycles? ChemPlusChem 2019, 84, 712-721.

24. Oruganti, B.; Wang, J.; Durbeej, B., Excited-State Aromaticity Improves Molecular Motors: A Computational Analysis. Org. Lett. 2017, 19, 4818-4821.

25. Streifel, B. C.; Zafra, J. L.; Espejo, G. L.; Gómez-García, C. J.; Casado, J.; Tovar, J. D., An Unusually Small Singlet-Triplet Gap in a Quinoidal 1,6-Methano[10]annulene Resulting from Baird's 4n $\pi$-Electron Triplet Stabilization. Angew. Chem. Int. Ed. 2015, 54, 5888-5893.

26. Jorner, K.; Feixas, F.; Ayub, R.; Lindh, R.; Solà, M.; Ottosson, H., Analysis of a Compound Class with Triplet States Stabilized by Potentially Baird Aromatic [10]Annulenyl Dicationic Rings. Chem. Eur. J. 2016, 22, 2793-2800.

$27 . \quad$ Kim, J.; Oh, J.; Park, S.; Zafra, J. L.; DeFrancisco, J. R.; Casanova, D.; Lim, M.; Tovar, J. D.; Casado, J.; Kim, D., Two-electron transfer stabilized by excited-state aromatization. Nature Commun. 2019, 10, 4983.

28. Ayub, R.; Bakouri, O. E.; Jorner, K.; Solà, M.; Ottosson, H., Can Baird's and Clar's Rules Combined Explain Triplet State Energies of Polycyclic Conjugated Hydrocarbons with Fused $4 n \pi$ - and $(4 n+2) \pi$-Rings? J. Org. Chem. 2017, 82, 6327-6340.

29. Cha, W.-Y.; Kim, T.; Ghosh, A.; Zhang, Z.; Ke, X.-S.; Ali, R.; Lynch, V. M.; Jung, J.; Kim, W.; Lee, S.; Fukuzumi, S.; Park, J. S.; Sessler, J. L.; Chandrashekar, T. K.; Kim, D., Bicyclic Baird-type aromaticity. Nature Chem. 2017, 9, 1243-1248.

$30 . \quad \mathrm{Wu}, \mathrm{C}$.-H.; Karas, L. J.; Ottosson, H.; Wu, J. I.-C., Excited-state proton transfer relieves antiaromaticity in molecules. Proc. Nat. Acad. Sci. 2019, 116, 20303-20308.

31. El Bakouri, O.; Smith, J. R.; Ottosson, H., Strategies for Design of Potential Singlet Fission Chromophores Utilizing a Combination of Ground-State and Excited-State Aromaticity Rules. J. Am. Chem. Soc. 2020, 142, 5602-5617.

32. Chen, D.; Szczepanik, D. W.; Zhu, J.; Solà, M., All-metal Baird aromaticity. Chem. Commun. 2020, 56, 12522-12525.

33. Mauksch, M.; Tsogoeva, S. B., A new architecture for high spin organics based on Baird's rule of $4 \mathrm{n}$ electron triplet aromatics. Phys. Chem. Chem. Phys. 2017, 19, 4688-4694.

34. Preethalayam, P.; Krishnan, K. S.; Thulasi, S.; Chand, S. S.; Joseph, J.; Nair, V.; Jaroschik, F.; Radhakrishnan, K. V., Recent Advances in the Chemistry of Pentafulvenes. Chem. Rev. 2017, 117, 3930-3989.

35. $\quad Y u$, D.; Rong, C.; Lu, T.; De Proft, F.; Liu, S., Baird's Rule in Substituted Fulvene Derivatives: An Information-Theoretic Study on Triplet-State Aromaticity and Antiaromaticity. ACS Omega 2018, 3, 18370-18379.

36. Yadav, S.; El Bakouri, O.; Jorner, K.; Tong, H.; Dahlstrand, C.; Solà, M.; Ottosson, H., Exploiting the Aromatic Chameleon Character of Fulvenes for Computational Design of BairdAromatic Triplet Ground State Compounds. Chem. Asian J. 2019, 14, 1870-1878.

37. Moroni, L.; Pagliai, M.; Chelli, R.; Pietraperzia, G.; Salvi, P. R.; Gellini, C., Photochemical Reactivity of 1,6-Methano[10]annulene. J. Phys. Chem. A 2017, 121, 4412-4421.

38. Fradera, X.; Austen, M. A.; Bader, R. F. W., The Lewis model and beyond. J. Phys. Chem. A 1999, 103, 304-314.

39. Fradera, X.; Poater, J.; Simon, S.; Duran, M.; Solà, M., Electron-pairing analysis from localization and delocalization indices in the framework of the atoms-in-molecules theory. Theor. Chem. Acc. 2002, 108, 214-224.

40. Kruszewski, J.; Krygowski, T. M., Definition of aromaticity basing on the harmonic oscillator model. Tetrahedron Lett. 1972, 13, 3839-3842.

41. Krygowski, T. M.; Cyrański, M. K., Structural Aspects of Aromaticity. Chem. Rev. 2001, $101,1385-1420$. 
42.

Matito, E.; Duran, M.; Solà, M., The aromatic fluctuation index (FLU): A new aromaticity index based on electron delocalization. J. Chem. Phys. 2005, 122, 014109, Erratum, ibid, 2006, 125, 059901.

43. $\quad$ Chen, Z.; Wannere, C. S.; Corminboeuf, C.; Puchta, R.; Schleyer, P. v. R., NucleusIndependent Chemical Shifts (NICS) as an Aromaticity Criterion. Chem. Rev. 2005, 105, 3842-3888.

44. Jusélius, J.; Sundholm, D.; Gauss, J., Calculation of current densities using gaugeincluding atomic orbitals. J. Chem. Phys. 2004, 121, 3952-3963.

45. Rauhalahti, M.; Taubert, S.; Sundholm, D.; Liégeois, V., Calculations of current densities for neutral and doubly charged persubstituted benzenes using effective core potentials. Phys. Chem. Chem. Phys. 2017, 19, 7124-7131.

46. Feixas, F.; Matito, E.; Poater, J.; Solà, M., Quantifying aromaticity with electron delocalisation measures. Chem. Soc. Rev. 2015, 44, 6434-6451.

47. Giambiagi, M.; de Giambiagi, M. S.; dos Santos Silva, C. D.; de Figueiredo, A. P., Multicenter bond indices as a measure of aromaticity. Phys. Chem. Chem. Phys. 2000, 2, 3381-3392.

48. Bultinck, P.; Ponec, R.; Van Damme, S., Multicenter bond indices as a new measure of aromaticity in polycyclic aromatic hydrocarbons. J. Phys. Org. Chem. 2005, 18, 706-718.

49. Cioslowski, J.; Matito, E.; Solà, M., Properties of Aromaticity Indices Based on the OneElectron Density Matrix. J. Phys. Chem. A 2007, 111, 6521-6525.

50. Matito, E., An electronic aromaticity index for large rings. Phys. Chem. Chem. Phys. 2016, 18, 11839-11846.

51. $\quad \mathrm{Wu}, \mathrm{Q}$.; Van Voorhis, T., Direct optimization method to study constrained systems within density-functional theory. Phys. Rev. A 2005, 72, 024502.

52. Chappell, J. S.; Bloch, A. N.; Bryden, W. A.; Maxfield, M.; Poehler, T. O.; Cowan, D. O., Degree of charge transfer in organic conductors by infrared absorption spectroscopy. J. Am. Chem. Soc. 1981, 103, 2442-2443.

53. Belova, V.; Beyer, P.; Meister, E.; Linderl, T.; Halbich, M.-U.; Gerhard, M.; Schmidt, S.; Zechel, T.; Meisel, T.; Generalov, A. V.; Anselmo, A. S.; Scholz, R.; Konovalov, O.; Gerlach, A.; Koch, M.; Hinderhofer, A.; Opitz, A.; Brütting, W.; Schreiber, F., Evidence for Anisotropic Electronic Coupling of Charge Transfer States in Weakly Interacting Organic Semiconductor Mixtures. J. Am. Chem. Soc. 2017, 139, 8474-8486.

54. $\quad$ Méndez, H.; Heimel, G.; Winkler, S.; Frisch, J.; Opitz, A.; Sauer, K.; Wegner, B.; Oehzelt, M.; Röthel, C.; Duhm, S.; Többens, D.; Koch, N.; Salzmann, I., Charge-transfer crystallites as molecular electrical dopants. Nature Commun. 2015, 6, 8560.

55. Talin, A. A.; Centrone, A.; Ford, A. C.; Foster, M. E.; Stavila, V.; Haney, P.; Kinney, R. A.; Szalai, V.; El Gabaly, F.; Yoon, H. P.; Léonard, F.; Allendorf, M. D., Tunable Electrical Conductivity in Metal-Organic Framework Thin-Film Devices. Science 2014, 343, 66-69.

56. Yuan, D., Stable $n$-Doped Conductors Enabled by Organic Diradicals. Chem 2019, 5, 744-745.

57. Takahashi, T.; Matsuoka, K.-i.; Takimiya, K.; Otsubo, T.; Aso, Y., Extensive Quinoidal Oligothiophenes with Dicyanomethylene Groups at Terminal Positions as Highly Amphoteric Redox Molecules. J. Am. Chem. Soc. 2005, 127, 8928-8929.

58. Shainyan, B. A.; Fettke, A.; Kleinpeter, E., Push-Pull vs Captodative Aromaticity. J. Phys. Chem. A 2008, 112, 10895-10903.

59. Karas, L. J.; Campbell, A. T.; Alabugin, I. V.; Wu, J. I., Antiaromaticity Gain Activates Tropone and Nonbenzenoid Aromatics as Normal-Electron-Demand Diels-Alder Dienes. Org. Lett. 2020, 22, 7083-7087. 